\title{
Measuring landscape evolution from inception to senescence
}

\author{
Nicholas Patton ( $\nabla$ nicholas.patton@pg.canterbury.ac.nz ) \\ University of Canterbury https://orcid.org/0000-0002-4137-0636 \\ James Shulmeister \\ University of Canterbury \\ Peter Almond \\ Lincoln University \\ Daniel Ellerton \\ University of Queensland \\ Gilles Seropian \\ University of Canterbury
}

\section{Physical Sciences - Article}

Keywords: Curvature, hillslope thresholds, soil diffusion, soil transport, erosion, dunes, natural laboratory

Posted Date: November 10th, 2020

DOl: https://doi.org/10.21203/rs.3.rs-99832/v1

License: (c) (i) This work is licensed under a Creative Commons Attribution 4.0 International License.

Read Full License 


\title{
Measuring landscape evolution from inception to senescence
}

\author{
*Nicholas R. Patton ${ }^{1,2}$, James Shulmeister ${ }^{1,2}$, Peter C. Almond ${ }^{3}$, \\ Daniel Ellerton ${ }^{2}$, and Gilles Seropian ${ }^{1}$
}

\footnotetext{
${ }^{1}$ School of Earth and Environment, University of Canterbury, Christchurch 8041, New Zealand

${ }^{2}$ School of Earth and Environmental Sciences, The University of Queensland, Brisbane 4072, Australia

${ }^{3}$ Department of Soil and Physical Sciences, Lincoln University, Christchurch 7647 New Zealand ${ }^{*}$ Corresponding Author
}

Nicholas R. Patton (nicholas.patton@pg.canterbury.ac.nz) James Shulmeister (james.shulmeister@canterbury.ac.nz)

Peter C. Almond (peter.almond@lincoln.ac.nz)

Daniel Ellerton (d.ellerton@uq.edu.au)

Gilles Seropian (gilles.seropian@pg.canterbury.ac.nz)

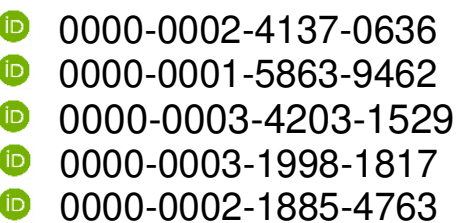

Key words: Curvature, hillslope thresholds, soil diffusion, soil transport, erosion, dunes, natural laboratory

\begin{abstract}
The concept of the geomorphic cycle is a foundational principle in geology and geomorphology, but the topographic evolution of a single landscape from inception to senescence has not been demonstrated in nature. The Cooloola Sand Mass (CSM) in eastern Australia preserves dune landforms from initial formation to the achievement of maturity (a morphologic steady-state) and its topographic evolution parallels that of physical based models of dry unconsolidated sand. Our field based measurements and forward numerical models demonstrate that this evolution is caused by nonlinear sediment transport governed by hillslope thresholds. Our findings confirm that physical models of landscape evolution are applicable at the landscape scale. We also propose that the distribution of curvature $(C)$ of a landform, and its associated standard deviation $\left(\sigma_{C}\right)$ represents a landscape's potential for change. Once $\sigma_{C}$ is normalised, it can be used to measure and define the evolution of topography and is an essential morphometric tool for understanding landscapes.
\end{abstract}

\section{Introduction}

The concept that the Earth's surface evolves through time from newly constructed landforms to denuded landscapes in topographic equilibrium is a foundational idea in geology and geomorphology ${ }^{1-3}$. The underpinning concept is that gravitationally driven transport processes act in tandem with erosion and deposition to relax landscapes towards their base-levels while reducing mean local relief ${ }^{3,4}$. It has not been possible to demonstrate the complete process in a natural setting. This is because the evolutionary pathway of a landscape incorporates multiple phases of relaxation and rejuvenation (stages in the geomorphic cycle) to produce the landscapes we observe today. Moreover, landscape evolution typically develops on geological time scales ${ }^{5}$ and few systems have adequate dating control over the full duration to investigate the entire process; nor are intermediate stages usually preserved. Consequently, most studies utilise space for time substitutions for their experimental design (e.g. Stolar et al. ${ }^{6}$ and Hilley \& Arrowsmith ${ }^{7}$ ); however, for timescales on multiple millennia, tectonic and climate forcings are rarely uniform and assumptions cannot be verified. In this paper, we highlight that the Cooloola Sand Mass (CSM) dune field in Australia is an ideal natural laboratory to evaluate landscape evolution because of its lithologic homogeneity, 
62

tectonic and climatic stability, and chronologic constraints on dune emplacement. Utilizing field observations and digital terrain analysis, we explain the evolution of 15 dated parabolic dunes spanning their entire geomorphic development $(0.23 \pm 0.05$ to $9.82 \pm 0.98 \mathrm{ka})$ and validate our results by simulating dune evolution, under varying soil transport conditions, as it approaches a morphologic steady-state. We consider only gravitational processes as Holocene sections of the CSM are not subject to fluvial processes.

\section{Curvature and landscape evolution}

Hillslope curvature $(\boldsymbol{C})$, the spatial rate of change of gradient from a fixed position in all directions $^{8}$, influences water flow paths ${ }^{9}$, nutrient redistribution ${ }^{10,11}$, and soil characteristics ${ }^{12}$. These consequently affect landscape evolution. Particularly, $\boldsymbol{C}$ has been used as a surrogate for mobile soil (regolith) thickness ${ }^{13-15}$ and in the derivation of soil production functions and erosion rates ${ }^{16-20}$.

In soil-mantled landscapes $C$ is inversely related to mobile soil thickness. Ridges and spurs $(\boldsymbol{C}<0)$ have the thinnest soils whereas the hollows and valleys $(\boldsymbol{C}>0)$ have the thickest soils ${ }^{13,15}$. According to commonly prescribed soil production functions (exponential or humped), production rates are the highest in thin soils and rates decrease as soil thickens ${ }^{21}$. Therefore, soil is primarily produced on ridges and displaced downslope to the hollows through diffusive sediment transport, whereby soil flux is solely gradient dependent (linear slopedependent transport). Sediment flux $\widetilde{\boldsymbol{q}_{S}}$ is equal to the product of hillslope gradient $\boldsymbol{S}^{1,2}$

$\widetilde{q_{S}}=-K S$,

Eq. 1)

where $\boldsymbol{K}$ is the soil transport coefficient. Past studies have focus on the convex sections of hillslopes where a balance between erosion and soil production can be established and a soil thickness steady-state can be demonstrated. It has been shown that increases in convexity (decrease in $\boldsymbol{C}$ ) corresponds with an increase in soil production and divergence of sediment flux, and erosion ${ }^{17,18}$. Less attention has been given to concave segments of hillslopes where sediment tends to accumulate ${ }^{13,22}$. Patton et al. ${ }^{15}$ observed that landscapes have equal proportions of convex and concave land area and the distribution of $\boldsymbol{C}$ is centred on planar surfaces $(\boldsymbol{C}=0)$. When evaluating landscapes from narrow to broad $\boldsymbol{C}$ distributions they noted an overall increase in erosion rates and variability in sediment transport styles (i.e. soil creep to landslides), which likely coincided with increasing local relief and hillslope gradients. Though not originally stated in their work, this implies that in landscapes with broad $\boldsymbol{C}$ distributions have a greater potential for change than landscapes with narrow $\boldsymbol{C}$ distributions. Here we suggest utilizing the standard deviation of $\boldsymbol{C}$ distribution $\left(\boldsymbol{\sigma}_{c}\right)$, as a metric to capture the variability in landscape drivers (i.e. soil production, transport, erosion, and deposition), which quantifies the potential of a landscape to change with time (stage of geomorphic cycle). We note that if soil transport is linearly related to hillslope gradient (i.e. Eq. 1 holds), then the erosion rate $\boldsymbol{E}$ is given by ${ }^{18}$

$E=\nabla \widetilde{q_{S}}=-K C$.

Therefore $\boldsymbol{E}$ is directly proportional to $\boldsymbol{C}$ hence $\boldsymbol{\sigma}_{c}$ captures the spatial variability of erosion rates and the potential for a landscape to smooth itself. We expect the time dependence of $\sigma_{c}$ to embody fundamental hillslope parameters and to demonstrate threshold crossing behaviour.

\section{Field area}

The Cooloola Sand Mass (CSM) in south eastern Queensland contains a series of coastal dune formations that extend back in age nearly $800 \mathrm{ka}$. The dune field comprises of $>150$ large parabolic dunes, many of which have been dated (i.e., Walker et al. ${ }^{23}$ and Ellerton et al. ${ }^{24}$ ) (Fig. 1). The on-lapping parabolic dunes provide a chronosequence through the 
Holocene. The outcome is a landscape increasing in age and soil development while decreasing in topographic variability moving inland from the coast (Fig. 1c). During the
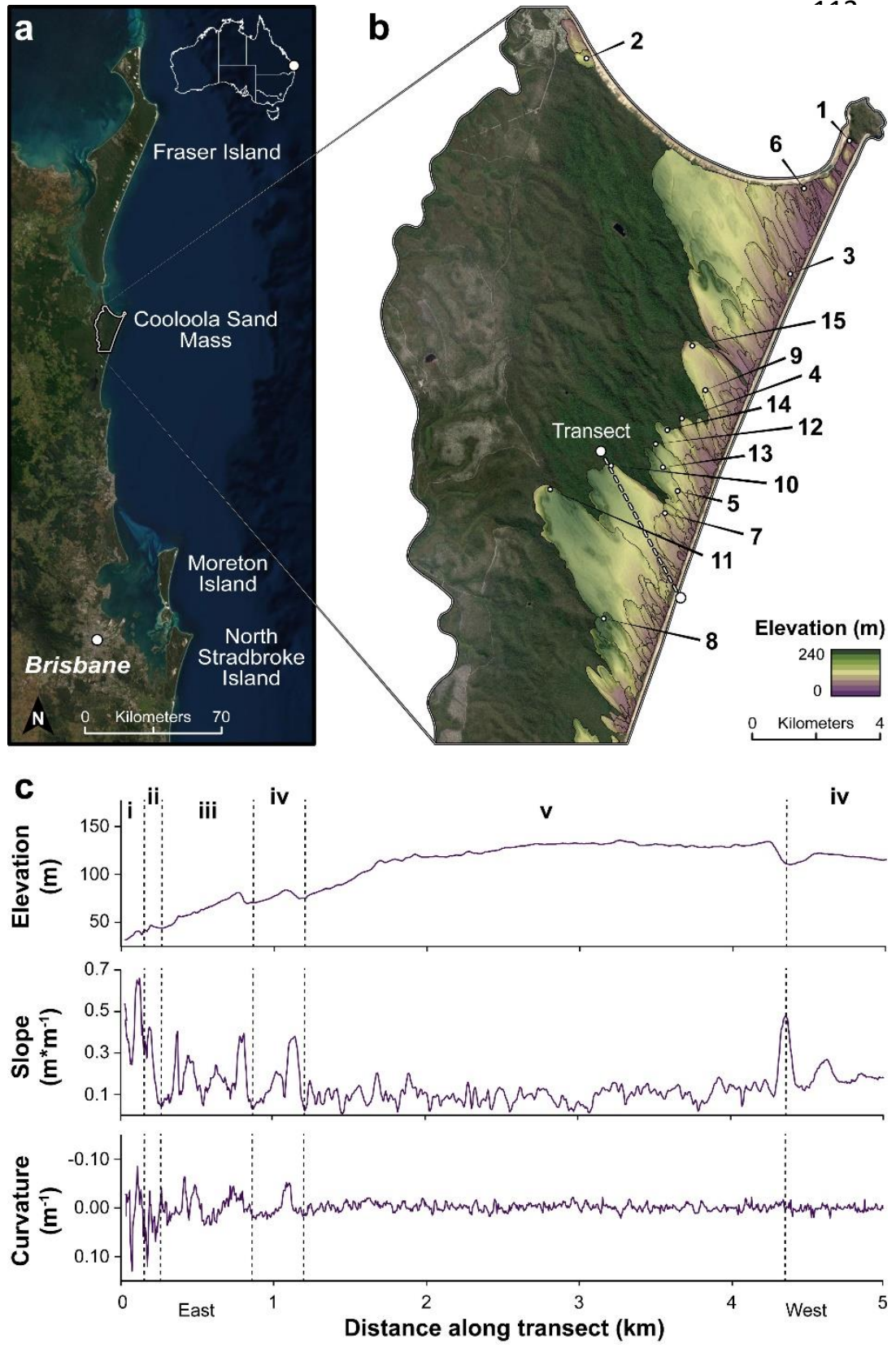

Holocene, large volumes of $(180-250 \mu \mathrm{m})$ quartz sand have been provided by the longshore drift system ${ }^{25}$, and the CSM is tectonically inactive with only minor eustatic/hydro-isostatic changes in local elevation (sea-level) of between +2 to $-0.5 \mathrm{~m}^{26}$. Proxy records indicate stable climate and vegetation during this period in coastal SE Queensland ${ }^{27}$.

Figure 1: Regional and site location. a) Satellite imagery of the South East Queensland Dune fields in Australia, emphasizing the location of the Cooloola Sand Mass. b) Delineated Holocene dunes and their associated elevation at a $5 \mathrm{~m}$ resolution and location of the 15 dated dunes used in this study (dots) (obtained from Walker et al. ${ }^{23}$ and Ellerton et al. ${ }^{24}$, see Extended Table 1). c) $A$ transect aligned parallel to the dominant wind direction, (southeast to northwest), seen in Panel $b$, highlights the transition from juvenile dunes (i) to more mature dunes (ii to vi). When dunes are emplaced, they have highly variable surface topography but as time continues, their slope relaxes towards a morphologic steady-state and this evolution can best be described by a dune's curvature (C), specifically a dune's standard deviation of curvature $\left(\boldsymbol{\sigma}_{c}\right)$.

The dunes are smooth and undissected, which is indicative of a dominance of diffuse grainby-grain processes ${ }^{28}$ and a lack of hillslope-scale water-driven transport. The absence of channels and fluvial processes is consistent with the characteristically high infiltration rates $\left(>600 \mathrm{~mm} \mathrm{hr}^{-1}\right)^{29}$, and few steep slopes, except on the lee faces of the dunes. Sediment removal from internal basins is negligible due to the absence of fluvial transport and dune onlapping, effectively making the CSM a closed system. Since the soil parent material (unconsolidated dune sands) and the soils they generate are virtually identical, soil thickness is unlimited, creating a truly transport limited system. The evolution of the landscape is not restricted by production of readily available material. All sediment eroded from the convex positions of the landscape is deposited in the concave positions. Hence there is a closed mass balance and lowering of the convex ridges (loss of elevation) can be accounted for in the concave hollows (gain of elevation), see Extended Fig.1. Consequently, the CSM is a natural laboratory that closely mimics idealized physical models of unconsolidated sediment (e.g. Roering et al. ${ }^{30}$, Roering ${ }^{31}$, Sweeney et al. ${ }^{32}$, Furbish et al. ${ }^{33}$, and Deshpande et al. ${ }^{34}$ ), provides 
a legitimate space for time substitution of landscape evolution, and retains the depositional legacy of hillslope erosion.

\section{Landscape evolution and hillslope thresholds}

In simulated dune evolution for $10 \mathrm{ka}$ on a young dune $(\sim 0.3 \mathrm{ka})$, we observe that the $\boldsymbol{C}$ distribution is symmetrically distributed with its mean centred on $\sim 0 \mathrm{~m}^{-1}$, and narrows with time (Fig. 2a and Extended Fig. 2). Simulations produced smooth decays of $\boldsymbol{\sigma}_{\mathcal{C}}$, the rate of decay increasing with higher $\boldsymbol{K}$ (Fig. 2b). Like the simulations all CSM dunes exhibit normal distributions of $\boldsymbol{C}$ of mean $\sim 0 \mathrm{~m}^{-1}$ (Fig. 2c) and whose $\boldsymbol{\sigma}_{c}$ decline by a factor of about 6 (from 0.074 to $0.012 \mathrm{~m}^{-1}$ ) as dunes increase in age. By contrast, the decline of $\sigma_{c}$ from the dunes followed a "hockey stick" form, showing a steep initial decay transitioning abruptly to a more gradual decline at a $\sigma_{c}$ of $0.03 \mathrm{~m}^{-1}$ (Fig $2 \mathrm{~d}$ and Extended Fig. 3). We observe a rapid relaxation of the highly convex dune crests within $\sim 1 \mathrm{ka}$ of emplacement which is best described with a $K$ value of $0.06 \mathrm{~m}^{2} \mathrm{yr}^{-1}$. This is abruptly followed by a phase of slower topographic adjustment reflecting a $K$ value of $0.002 \mathrm{~m}^{2} \mathrm{yr}^{-1}$ which ultimately reaches a morphologic steady-state $\left(d \sigma_{d} d t \rightarrow 0\right)$ by the late Holocene, a phenomenon that continues for all the Pleistocene dunes (grey squares in Fig. 2d).

This kind of threshold soil transport behaviour has been demonstrated in sandbox experiments and modelled as non-linear slope dependent transport ${ }^{35}$. The associated transport equation includes a soil transport coefficient that increases as a function of gradient $\boldsymbol{S}$. Our simulations do not incorporate non-linear transport equations, but the steep "handle of the hockey stick" parallels our simulations of the decay of $\boldsymbol{\sigma}_{c}$ at high $\boldsymbol{K}$, which act as a proxy for this behaviour. That the "blade of the hockey stick" does not follow the high $K$ simulations is evidence of the transport regime shift at $\sigma_{C}>0.03 \mathrm{~m}^{-1}$. We propose this pattern derives from a threshold behaviour triggered by hillslope gradient during periods when dunes are devegetated by fires. Burning switches the dunes from essentially slow linear slope-dependent soil transport to nonlinear transport, but where the non-linear enhancement of transport is only manifested on the younger, steeper dunes of high $\sigma_{c}$ (Extended Fig. 5)

a
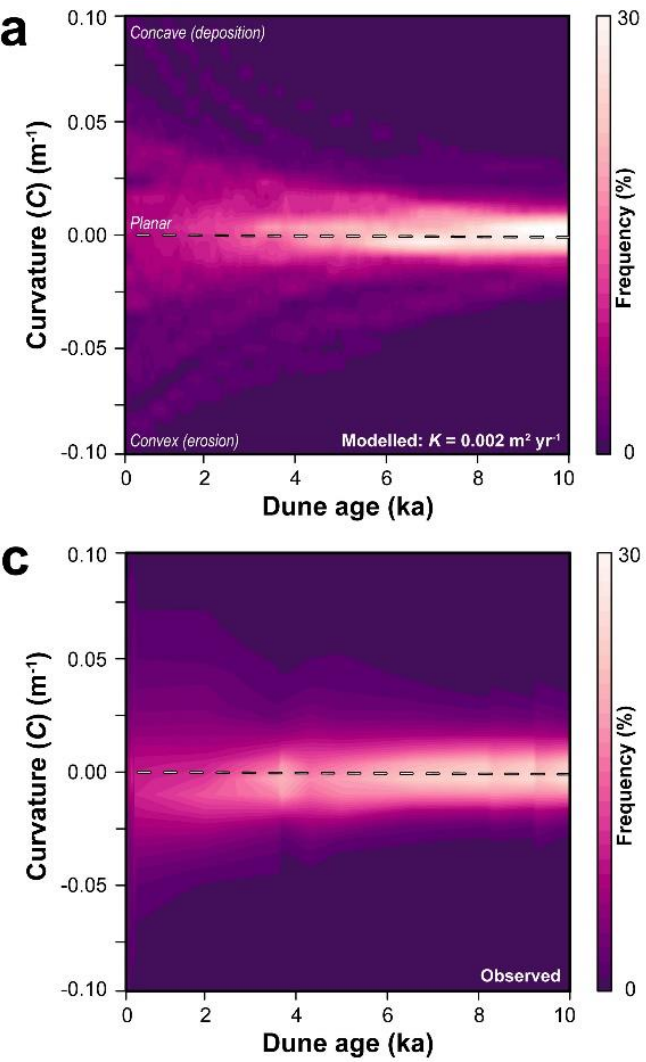

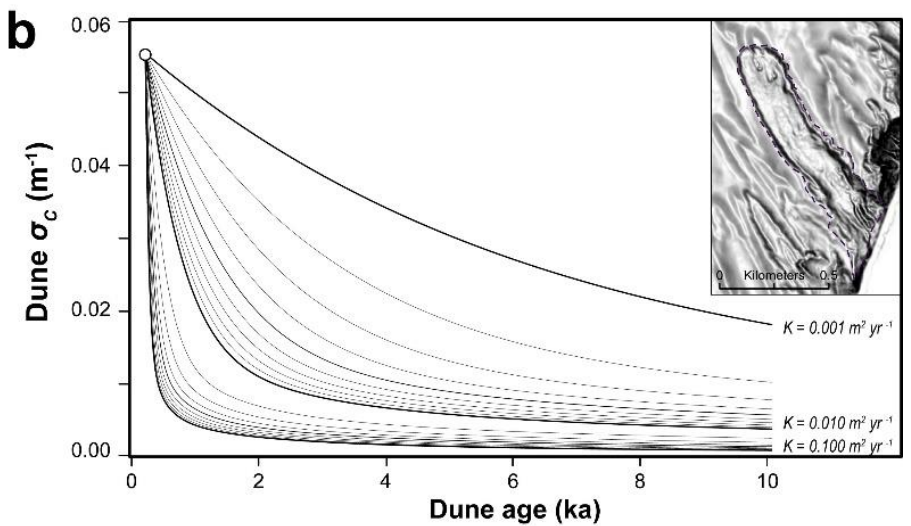

b

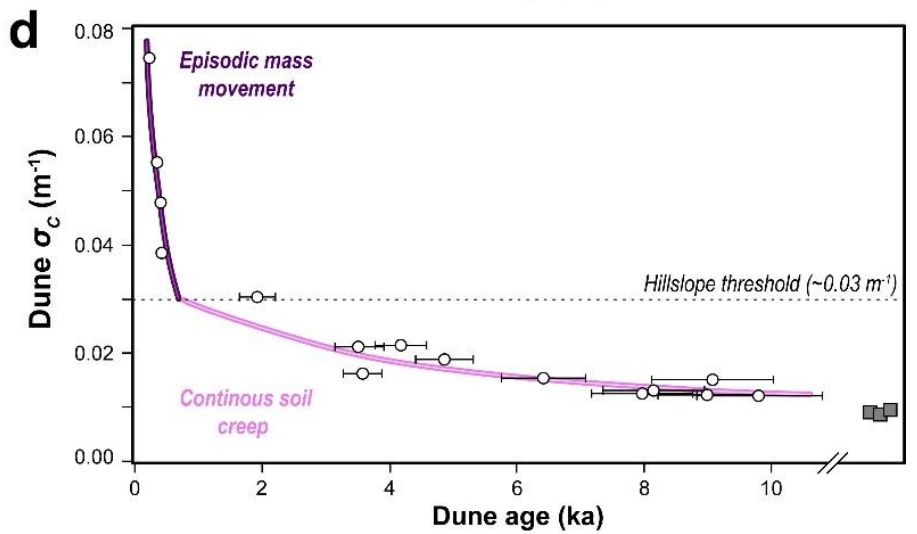


Figure 2: Simulated verses observed landscape evolution. a) Distributions of curvatures for simulated evolution of a juvenile dune (insert in panel b) with a constant soil transport coefficient (K) value of $0.002 \mathrm{~m}^{2} \mathrm{yr}^{1}$, see Extended Fig. 2 and 3. Note the normal distribution of curvature $(\boldsymbol{C})$ centred on planar topography $\left(0 \mathrm{~m}^{-1}\right)$ and the gradual narrowing of distributions with time (dark to light frequency). b) Simulated evolution of dune standard deviation of curvature $\left(\boldsymbol{\sigma}_{c}\right)$ for $10 \mathrm{ka}$, under varying $\boldsymbol{K}$ values. c) Observed $\boldsymbol{C}$ distributions for the 15 dated CSM dunes which mirror simulated outcomes in Panel a. d) Plotted dune $\sigma_{c}$ with time (with error bars, $\pm 1 \sigma$ ), white dots and visual trend line. CSM evolution is best described by two $K$ values. When dunes $\sigma_{c}$ are greater than the hillslope threshold ( $0.03 \mathrm{~m}^{-1}$, dashed line), $\boldsymbol{K}$ is $0.06 \mathrm{~m}^{2} \mathrm{yr}^{-1}$ (purple line) which reflects the dominance of episodic mass movement (dry ravel and sheet-wash $(n=4)$ ). After dunes are lowered below the hillslope threshold, $\boldsymbol{K}$ is $0.002 \mathrm{~m}^{2} \mathrm{yr}^{-1}$ (pink line) where slow and continuous soil transport occurs (soil creep $(n=11)$ ), see Extended Fig. 3. This behaviour continues as a morphologic steady-state approximated by Pleistocene age dunes (grey squares, not included in this analysis) is approached.

Field observations at the CSM support our claims. Across the CSM, the freely drained soils with high infiltration rates should limit dune evolution to slow continuous sediment transport; however, wildfires are a common disturbance ${ }^{36}$ which remove vegetation and produce hydrophobic surface soils ${ }^{37,38}$. As a result, local soil transport efficiency $(\boldsymbol{K})$ increases as hillslopes near their angle of repose (angle of $33^{\circ}$ or slope of $0.65 \mathrm{~m}^{*} \mathrm{~m}^{-1}$ ) experience episodic mass movements in the form of dry ravelling and sheet-washing ${ }^{39}$. The sharp convex slope elements are rounded and steep-sided swales infill, corresponding to a rapid decline in $\boldsymbol{\sigma}_{c}$. These punctuated disturbances reduce soil residence time in both erosional and depositional sites and limit soil development. Although fires occur with constant frequency and across dunes of all ages, higher erosion rates caused by episodic mass movement is limited to the first $1 \mathrm{ka}$ of dune development. In this phase, hillslope gradients are near their angle of repose, ridge crests are narrow, and as a consequence $\sigma_{c}$ is greater than $\sim 0.03 \mathrm{~m}^{-1}$ (Fig. 2, Extended Table 2, and Extended Fig. 4), thus indicating a potential hillslope mechanism threshold ${ }^{40}$. After dunes reduce to less than $\sim 0.03 \mathrm{~m}^{-1}$, gradual transport regimes controlled by soil creep processes dominate (i.e. granular relaxation, bioturbation, and rain splash $^{33,34,41,42}$ ), soil residence times increase, and podsolization is well expressed in the world's thickest soils, Giant Podzols ${ }^{43}$.
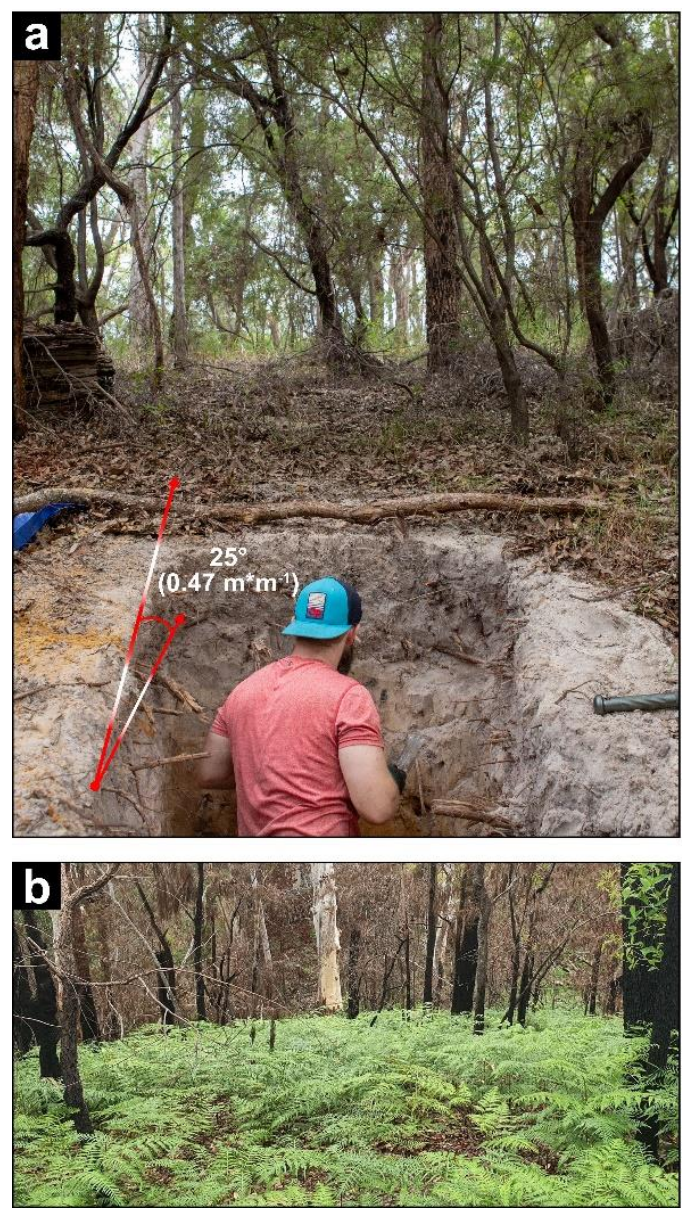

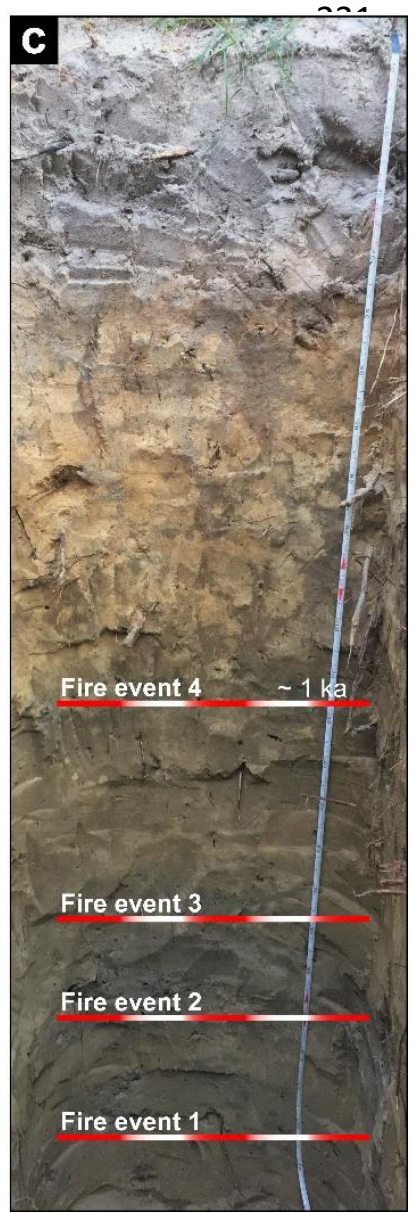

Figure 3: Surface images of dune slopes and soil profiles. a) Typical hillslope at the Cooloola Sand Mass looking up to dune crest. b) Same dune as Panel a looking down slope after being severely burnt in the "Freshwater Road Fire" on December 15th, 2019. Note, within three months the rapid reestablishment of vegetation covers and stabilizes the landscape. c) Depositional footslope of a $\sim 2 k a$ dune and stratified layers of charcoal associated with fire induced mass movement (dry ravelling and sheet-washing) oldest (fire event \#1) to youngest (fire event \#4). Distinct layers can be observed within the first $1 \mathrm{ka}$ (unpublished charcoal radiocarbon age) of dune deposition. As time progresses, charcoal layers become more diffuse and eventually become disseminated evenly throughout the profile, highlighting the transition between episodic to continuous sediment transport on dune evolution. 
In fact, a major fire event in 2019 showed evidence of mass movement only on younger dunes (inception through adolescence), initiating on steep, lee hillslopes near sharp, convex dune crests. Though short-lived, the landscape was efficiently smoothed by lowering local highs and filling local lows ${ }^{44}$. Within three months, the disturbed portions of the landscape were stabilized by new vegetation growth (Fig. 3b). Past disturbance events are recorded as stratified charcoal layers in depositional footslopes. Within the early stages of dune evolution, the depositional portions of the landscape have abundant and distinct stratified layers of charcoal. As time progresses, these layers become more diffuse and eventually charcoal is evenly disseminated through the profile due to the influence of slow continuous transport and mixing (Fig. 3c). These records are found at all excavated footslope positions and demonstrate the regularity of wildfire and the consistency in the transition from episodic to continuous soil transport processes is across the landscape.

\title{
Conclusion
}

\begin{abstract}
Hillslope curvature's $(\boldsymbol{C})$ connection with key processes in landscape evolution has prompted a closer examination to how its distribution evolves with time. We propose that the standard deviation of this distribution $\left(\sigma_{C}\right)$ is a proxy for a landscape's potential to change. The significance of this parameter stems from $\boldsymbol{C}$ s inherent coupling with slope which governs gravitational driven erosion, deposition and transport processes that reduce local relief. When $\boldsymbol{C}$ distributions are broad (larger $\boldsymbol{\sigma}_{\boldsymbol{C}}$ values) erosion and deposition rates are higher with a wider variety of transport styles compared to narrow distributions (smaller $\boldsymbol{\sigma}_{\mathrm{c}}$ values). If given adequate time eroding $d \sigma_{c} / d t \rightarrow 0$ indicating a lack of local relief and landform senescence, see Extended Fig. 6
\end{abstract}

The application of $\boldsymbol{\sigma}_{c}$ has been tested on a singular idealized chronosequence, and this system provides an end member example of a transport limited system where no valley processes are present. Changes in $\sigma_{c}$ value correspond with a shift in dominant transport mechanisms observed for soil-mantled landscapes ${ }^{15}$ which may indicate that $\sigma_{c}$ is a generalizable topographic metric. As highlighted by reviews across the geosciences (e.g. Jerolmack \& Daniels ${ }^{45}$, Tucker \& Hancock ${ }^{46}$, Minasny et al. ${ }^{47}$, Pawlik \& Samonil ${ }^{48}$, and Richter et al. ${ }^{21}$ ) identifying landscapes that can facilitate the integrated merger of interdisciplinary methods is vital for the understanding of earth systems processes. The Cooloola Sand Mass (CSM) provides such a system. The CSM records and preserves the evolution of dune landforms from inception to topographic senescence and demonstrates how transport processes, erosion and deposition act in tandem with topography to relax landscapes. Moreover, diffusional processes dominate at CSM and the assumption of equality of mass fluxes from erosional into depositional positions is valid, whereas this is not generally true, or at least demonstrable, in most landscapes. The conditions at the CSM parallel many physical based models of idealized systems. It validates landscape evolution inferences from physical modelling ${ }^{31}$ and supports the coupling between granular material physics and landscape change ${ }^{45}$. 

Dune selection and OSL dating overview. We focus on the Holocene sections of the Cooloola Sand Mass (CSM) as dated by Walker et al. ${ }^{23}$ and Ellerton et al. ${ }^{24}$ and mapped by Ward ${ }^{48}$ and Patton et al. ${ }^{49}$. Small aliquot ${ }^{24}$ and single grain ${ }^{23}$ Optically Stimulated Luminescence (OSL) ages for dunes were acquired from previously published sources. Dates represent the time of dune emplacement (inception) and consequently the initiation of dune relaxation. We choose to select ages from either dune apices or along the crest of the trailing ridges to ensure primary aeolian deposition. Additionally, samples collected at depths of less than $1.5 \mathrm{~m}$ were disregarded to avoid post-depositional mixing (i.e. bioturbation) and to reduce the risk of complex cosmic dose rate histories. In total, 15 dunes met our criteria, see Extended Table 1. Any dunes with multiple ages, were averaged and the resultant ages were utilized to produce the $\sigma_{c}$-age relationship. Additionally, three Pleistocene aged dunes, as defined by previous published work ${ }^{23,24,48,49}$, were delineated to provide a topographic end member for our analyses (not incorporated within the $\boldsymbol{\sigma}_{c}$-age relationship).

Dune delineation. We use high resolution elevation data, satellite imagery and a series of field campaigns to identify and validate our mapping efforts. Principally, we used publicly available $2 \mathrm{~m}$ resolution digital elevation model (DEM) derived from Light Detection and Ranging (LiDAR) (2011 Queensland LiDAR data) and Orthophoto imagery (1:5000) acquired through Queensland Globe. Dated dunes are individually defined as polygons in ArcMAP and delineated at the base of crests and trailing arms. A more detailed explanation of our mapping procedures can be found in Patton et al. ${ }^{49}$. Each dune was allocated into a geomorphic stage according to definitions given in Extended Table 2.

Selection of topographic indices. In this study we have evaluated the application of common morphometric variables such as elevation, slope, curvature for all delineated dunes. We elected to resample the original DEM using bilinear interpolation to a $5 \mathrm{~m}$ resolution to dampen topographic noise, removing DEM artefacts, and decrease roughness associated with dense vegetation ${ }^{49,50}$. Each layer was produced in ArcGIS (version 10.6) spatial analysis tools and calculated to the same extent.

Ultimately curvature $(\boldsymbol{C})$, and more specifically the standard deviation of curvature $\left(\boldsymbol{\sigma}_{c}\right)$ was chosen for our study for four main reasons:1) $\boldsymbol{C}$ and $\boldsymbol{\sigma}_{\boldsymbol{C}}$ normalise for antecedent topography on which dunes were emplaced, and allow us to compare dunes of varying ages across the whole dune field. Curvature is the first derivative of gradient (i.e. the spatial rate of change of gradient) and hence is insensitive to gradient biases introduced by broad-scale topography. Despite initial similarity in most respects, antecedent topography plays a role in controlling initial slope conditions. Dunes that have advanced over a flat plain have internal basins with different (lower) slopes than those that have advanced through previously emplaced dunes sequences (Fig. 1C). A desirable feature of $\boldsymbol{C}$ is that all landforms' curvature distributions are centred at zero, which makes it possible to make straight forward comparisons between dunes' $\boldsymbol{\sigma}_{c}$ values. 2) $\boldsymbol{C}$ is a proxy for soil production ${ }^{13}$, soil thickness ${ }^{15}$, and governs the convergence and divergence of sediment transport. Thus making $\boldsymbol{C}$ a logical candidate to describe landscape evolution. 3) $\boldsymbol{\sigma}_{c}$ provides unique values, which follows Hani et al.'s ${ }^{51}$ recommendations for ideal morphometric variables. 4) More complex methods have been used to describe topographic variability (e.g. root mean squared-based models, two dimensional variograms, and wavelet lifting schemes); however, the difference between each method's outcome is likely insignificant and largely site specific (see Berti et al. ${ }^{50}$ for more detail).

The values of $\boldsymbol{C}$ is a commonly utilized parameter in ArcGIS and the calculation of its standard deviation is an easily applied procedure. Curvature was calculated using the equation derived from Zevenberger and Thorne ${ }^{52}$ and Moore et al. ${ }^{7}$, which is ArcGIS's primary curvature output. However, this curvature function differentiates the slope in percent rather than the actual 
gradient, and reverses the sign, so to compute curvature values in units $1 \mathrm{~m}^{-1}$, we divide the ArcGIS output by -100 . This makes positive values represent concavity (hollows) and negative values represent convexity (ridges/spurs). Zonal statistics provided all topographic values used in this study and can be found in Extended Table 1. Any areas that are presently active (e.g. local reactivation), recently disturbed (e.g. streets, mines, and buildings), and/or currently water affected (e.g. lakes, and swamps) were removed and not included within our statistical analysis. Note, $\boldsymbol{C}$ and $\boldsymbol{\sigma}_{c}$ are extremely sensitive to the quality of the original elevation model or changes to boundary conditions (i.e., extent of the DEM and/or shape and size which zonal statistics were calculated), methodology, and/or processes. Special care was taken to eliminate these potential errors. Minor variability in absolute values may occur; however, overall trends remain the same.

Modelled dune evolution. We utilize topography from the CSM and run a one-dimensional landscape evolution model for a model time of $10 \mathrm{ka}$. A $1.13 \mathrm{~km}$ transect from a young dune $(\sim 0.3 \mathrm{ka})^{49}$ with elevation extracted every $5 \mathrm{~m}$ is used, see Extended Fig. 2 . The simulated land surface evolves by solving Eq. 2 using a forward finite difference scheme with yearly time steps. At each time step curvature is calculated from the second derivative of a quadratic function fitted over a 3-point moving window. The calculated erosion rate is then multiplied by the time step to compute land surface lowering (erosion) or rise (deposition). The standard deviation of the curvature distribution $\sigma_{c}$ is calculated every 50 years. We performed 30 simulations for $\boldsymbol{K}$ values in the range $0.001-0.01 \mathrm{~m}^{2} \mathrm{yr}^{-1}$, to produce general $\boldsymbol{\sigma}_{c}$-age relationships. These are then normalized to allow comparison with natural data. Due to the observed hillslope threshold $\left(\sigma_{c}=0.03 \mathrm{~m}^{-1}\right)$, we ran additional models using two different $K$ values for before and after the hillslope threshold has been met. Note, $\sigma_{c}$-age relationships could not be explained well with simple functions (e.g., two or three parameter exponentials); therefore, we selected $\boldsymbol{K}$ values based on observed goodness of fit when $\boldsymbol{\sigma}_{c}$ is normalized. We focus on the relative changes in dune evolution when $\boldsymbol{K}$ changes. The absolute values of $K$ are beyond the scope of the project but will be addressed in future studies.

Data availability. All datasets necessary to generate our results during the current study are available at (Address here). All soil samples at the CSM are located at The University of Queensland School of Earth and Environmental Science.

Code availability. All code necessary to generate our results during the current study are available at (Address here).

\section{Declaration of competing interest}

The authors declare that they have no known competing financial interests or personal relationships that could have appeared to influence the work reported in this paper.

\section{Acknowledgements}

The field work and mapping was undertaken using permit WITK15791415. Funding for this study was provided by the Australian Research Council (ARC) grant number DP150101513. We thank the assistance provided to us by the National Parks and Wildlife Service. We would also like to thank the valuable comments and suggestions on the development of this manuscript by Tim Stahl. Lastly we would like to acknowledge the traditional owners of the Cooloola Sand Mass (the Butchulla and Kabi' Kabi' peoples) and their elders past, present and emerging.

\section{Author Contributions}

N.R.P. formulated the idea of the manuscript. N.R.P., D.E. and J.S. carried out field work and the analyses. N.R.P. and J.S. drafted the manuscript with inputs from D.E., G.S. and P.C.A. P.C.A., G.S. and N.R.P. modelled landscape evolution. All authors assisted with writing and editing the manuscript. 
2) Gilbert, G. K. The convexity of hilltops. J. Geol. 17, 344-350 (1909).

3) Montgomery, D. R. Slope distributions, threshold hillslopes, and steady-state topography. Am. J. Sci. 301, 432-454 (2001).

4) Carson, M. A. \& Kirkby, M. J. Hillslope Form and Process (Cambridge Univ. Press, New York, (1972)).

5) Fernandes, N. F. \& Dietrich, W. E. Hillslope evolution by diffusive processes: The timescale for equilibrium adjustments. Water Resources Research 33, 1307-1318 (1997).

6) Stolar, D. B., Willett, S. D., \& Montgomery, D. R Characterization of topographic steady state in Taiwan. Earth and Planetary Science Letters. 261(3-4), 421-431 (2007).

7) Hilley, G. E., \& Arrowsmith, J. R. Geomorphic response to uplift along the Dragon's Back pressure ridge, Carrizo Plain, California. Geology. 36(5), 367-370 (2008).

8) Moore, I. D., Grayson, R. B. \& Landson, A. R. Digital terrain modeling: a review of hydrological, geomorphological, and biological applications. Hydrological Processes. 5, 3-30 (1991).

9) Bogaart, P. W., \& Troch, P. A. Curvature distribution within hillslopes and catchments and its effect on the hydrological response. Hydrology and Earth System Sciences Discussions, European Geosciences Union. 3 (3), 1071-1104. (2006).

10) Ritchie, J. C., McCarty, G. W., Venteris, E. R., \& Kaspar, T. C. Soil and soil organic carbon redistribution on the landscape. Geomorphology. 89(1-2), 163-171 (2007).

11) Patton, N. R., Lohse, K. A., Seyfried, M. S., Godsey, S. E., \& Parsons, S. B. Topographic controls of soil organic carbon on soil-mantled landscapes. Scientific reports. 9(1), 1-15 (2019).

12) Minasny, B., \& McBratney, A. B. Digital soil mapping: A brief history and some lessons. Geoderma. 264, 301-311 (2016).

13) Heimsath, A. M., Dietrich, W. E., Nishiizumi, K. \& Finkel, R. C. Cosmogenic nuclide, topography, and the spatial variation of soil depth. Geomorphology 27, 151-172 (1999).

14) Catani, F., Segoni, S., \& Falorni, G. An empirical geomorphology-based approach to the spatial prediction of soil thickness at catchment scale. Water Resources Research. 46(5) (2010).

15) Patton, N. R., Lohse, K. A., Godsey, S. E., Crosby, B. T., \& Seyfried, M. S. Predicting soil thickness on soil mantled hillslopes. Nature communications. 9(1), 1-10 (2018).

16) Dietrich, W. E., Reiss, R., Hsu, M. L. \& Montgomery, D. R. A process-based model for colluvial soil depth and shallow landsliding using digital elevation data. Hydrol. Proc. 9, 383-400 (1995).

17) Heimsath, A., Dietrich, W., Nishiizumi, K. et al. The soil production function and landscape equilibrium. Nature 388, 358-361 (1997).

18) Hurst, M. D., Mudd, S. M., Walcott, R., Attal, M., \& Yoo, K. Using hilltop curvature to derive the spatial distribution of erosion rates. Journal of Geophysical Research: Earth Surface. 117(2012).

19) Hurst, M. D., Mudd, S. M., Yoo, K., Attal, M., \& Walcott, R. Influence of lithology on hillslope morphology and response to tectonic forcing in the northern Sierra Nevada of California. Journal of Geophysical Research: Earth Surface. 118(2), 832-851(2013).

20) Gabet, E. J. et al. Local topography and erosion rate control regolith thickness along a ridgeline in the Sierra Nevada, California. Earth Surfurface Process Landforms 40, 1779-1790 (2015).

21) Richter, D. D., Eppes, M. C., Austin, J. C., Bacon, A. R., Billings, S. A., Brecheisen, Z., ... \& Wade, A. M. Soil production and the soil geomorphology legacy of Grove Karl Gilbert. Soil Science Society of America Journal. 84(1), 1-20 (2020).

22) Culling, W. E. H. Soil creep and the development of hillside slopes. The Journal of Geology. 71(2), 127-161 (1963).

23) Walker, J., Lees, B., Olley, J., \& Thompson, C. Dating the Cooloola coastal dunes of south-eastern Queensland, Australia. Marine Geology. 398, 73-85 (2018).

24) Ellerton, D., Rittenour, T., Shulmeister, J., Gontz, A., Welsh, K. J., \& Patton, N. An 800 kyr record of dune emplacement in relationship to high sea level forcing, Cooloola Sand Mass, Queensland, Australia. Geomorphology. 354, 106999 (2020). 
25) Boyd, R., Ruming, K., Goodwin, I., Sandstrom, M., \& Schröder-Adams, C. Highstand transport of coastal sand to the deep ocean: A case study from Fraser Island, southeast Australia. Geology 36.1, 15-18 (2008).

26) Lewis, S. E., Wüst, R. A., Webster, J. M., \& Shields, G. A. Mid-late Holocene sea-level variability in eastern Australia. Terra Nova. 20.1, 74-81 (2008).

27) Barr, C., Tibby, J., Moss, P. T., Halverson, G. P., Marshall, J. C., McGregor, G. B., \& Stirling, E. A 25,000-year record of environmental change from Welsby Lagoon, North Stradbroke Island, in the Australian subtropics. Quaternary International. 449, 106-118 (2017).

28) Perron, J. T., Dietrich, W. E., \& Kirchner, J. W. Controls on the spacing of first-order valleys. Journal of Geophysical Research: Earth Surface. 113 (2008).

29) Reeve, R., Fergus, I.F., \& Thompson, C.H. Studies in landscape dynamics in the Cooloola-Noosa River area, Queensland. 4. Hydrology and water chemistry. In: CSIRO Aust. Div. Soils Divisional Report No. 73, 42 (1985).

30) Roering, J. J., Kirchner, J. W., \& Dietrich, W. E. Hillslope evolution by nonlinear, slope-dependent transport: Steady state morphology and equilibrium adjustment timescales. Journal of Geophysical Research: Solid Earth. 106(B8), 1649916513 (2001).

31) Roering, J. J. Soil creep and convex-upward velocity profiles: Theoretical and experimental investigation of disturbance-driven sediment transport on hillslopes, Earth Surf. Processes Landforms, 29, 1597-1612 (2004).

32) Sweeney, K. E., Roering, J. J., \& Ellis, C. Experimental evidence for hillslope control of landscape scale. Science. 349(6243), 51-53 (2015).

33) Furbish, D. J., K. K. Hamner, M. Schmeeckle, M. N. Borosund, \& S. M. Mudd. Rain splash of dry sand revealed by high-speed imaging and sticky paper splash targets, J. Geophys. Res., 112 (2007).

34) Deshpande, N., Furbish, D., Arratia, P., \& Jerolmack, D. The perpetual fragility of creeping hillslopes (2020).

35) Roering, J. J., Kirchner, J. W., \& Dietrich, W. E. Evidence for nonlinear, diffusive sediment transport on hillslopes and implications for landscape morphology. Water Resources Research. 35(3), 853-870 (1999).

36) Moss, P., Dudgeon, A., Shapland, F., Withers, L., Brownhall, C., Terzano, D. \& Sloss, C. Investigation into the vegetation and fire history of the EPBC, Ramsar and WHA wetlands of the Great Sandy Straits, south east Queensland (2013).

37) Bridge, B. J., \& Ross, P. J. Water erosion in vegetated sand dunes at Cooloola, south-east Queensland. Zeitschrift für Geomorphologie. Supplementband 45, 227-244 (1983).

38) Thompson, C. H., \& Walker, J. Temporal changes in soils and vegetation on subtropical coastal dunes, Cooloola, Queensland, Australia-a synthesis. In Proc. Welsh Soils Discussion Group Meeting 'Soils and the Time Factor', Aberystwyth (1983).

39) Roering, J. J., \& Gerber, M. Fire and the evolution of steep, soil-mantled landscapes. Geology, 33(5), 349-352 (2005).

40) Carson, M. A., \& Petley, D. J. The existence of threshold hillslopes in the denudation of the landscape. Transactions of the Institute of British Geographers. 71-95 (1970).

41) Gabet, E. J. Gopher bioturbation: field evidence for non-linear hillslope diffusion. Earth Surface Processes and Landforms. 25(13), 1419-1428 (2000).

42) Pawlik, Ł., \& Šamonil, P. Soil creep: the driving factors, evidence and significance for biogeomorphic and pedogenic domains and systems-a critical literature review. Earth-Science Reviews. 178, 257-278 (2018).

43) Thompson, C. H. Podzol chronosequences on coastal dunes of eastern Australia. Nature, 291(5810). 59-61(1981).

44) Jyotsna, R., \& P. K. Haff. Microtopography as an indicator of modern hillslope diffusivity in arid terrain, Geology, 25, 695-698 (1997).

45) Jerolmack, D. J., \& Daniels, K. E. Viewing Earth's surface as a soft-matter landscape. Nature Reviews Physics, 1-15 (2019).

46) Tucker, G. E., \& Hancock, G. R. Modelling landscape evolution. Earth Surface Processes and Landforms, 35(1), 2850 (2010).

47) Minasny, B., Finke, P., Stockmann, U., Vanwalleghem, T., \& McBratney, A. B. Resolving the integral connection between pedogenesis and landscape evolution. Earth-Science Reviews, 150, 102-120 (2015). 
48) Ward, W. T. Coastal dunes and strandplains in southeast Queensland: sequence and chronology. Australian Journal

49) Patton, N. R., Ellerton, D., \& Shulmeister, J. High-resolution remapping of the coastal dune fields of south east Queensland, Australia: a morphometric approach. Journal of Maps. 15(2), 578-589 (2019).

50) Berti, M., Corsini, A., \& Daehne, A. Comparative analysis of surface roughness algorithms for the identification of active landslides. Geomorphology. 182, 1-18 (2013).

51) Hani, A. F. M., Sathyamoorthy, D., \& Asirvadam, V. S. A method for computation of surface roughness of digital elevation model terrains via multiscale analysis. Computers \& Geosciences 37(2), 177-192 (2011).

52) Zevenbergen, L. W. \& Thorne, C. R. Quantitative analysis of land surface topography. Earth Surface Process Landforms. 12, 47-56 (1987). 
625

626

627

628

629

630

631

632

633

634

635

636

637

638

\section{${ }^{*}$ Nicholas R. Patton ${ }^{1,2}$, James Shulmeister ${ }^{1,2}$, Peter C. Almond ${ }^{3}$ Daniel Ellerton ${ }^{2}$, and Gilles Seropian ${ }^{1}$}

\footnotetext{
${ }^{1}$ School of Earth and Environment, University of Canterbury, Christchurch 8041, New Zealand

${ }^{2}$ School of Earth and Environmental Sciences, The University of Queensland, Brisbane 4072, Australia

${ }^{3}$ Department of Soil and Physical Sciences, Lincoln University, Christchurch 7647 New Zealand
} ${ }^{*}$ Corresponding Author

Extended Table 1: Age data and supporting information used in Fig. 1, Fig. 2., and Extended Fig. 3 * Indicates the area of the dune at the surface. Indicates the distance dune travel, parallel to trailing arm, from the current coastline position to its furthest inland extent.

\begin{tabular}{|c|c|c|c|c|c|c|c|c|c|c|c|c|c|}
\hline$\underline{\text { Map }}$ & $\frac{\text { Age }}{\underline{(\text { ka) }}}$ & $\frac{\text { Average }}{\text { age (ka) }}$ & $\frac{\frac{\text { Age }}{\text { error }}}{\underline{\text { (ka) })}}$ & $\frac{{ }^{* \text { Dune }}}{\frac{\text { area }}{\left(\mathrm{km}^{2}\right)}}$ & $\frac{\frac{{ }^{t} \text { Dune }}{\text { length }}}{\frac{\text { from }}{\text { coast }}}$ & $\frac{\frac{\text { Mean }}{\text { slope }}}{\frac{\left(\mathrm{m}^{*} \mathrm{~m}^{-1}\right)}{n^{\prime}}}$ & $\frac{\frac{\text { Standard }}{\text { deviation }}}{\frac{\text { of slope }}{\left(\mathrm{m}^{\star} \mathrm{m}^{-1}\right)}}$ & $\frac{\text { Hillslope }}{\underline{\sigma_{c}\left(m^{-1}\right)}}$ & $\frac{\text { Profile }}{\underline{\sigma_{c}\left(m^{-1}\right)}}$ & $\frac{\text { Evolutionary }}{\text { stage }}$ & $\begin{array}{l}\text { Dating } \\
\text { method }\end{array}$ & Lab ID & $\underline{\text { References }}$ \\
\hline 1 & 0.23 & 0.23 & 0.05 & 0.065 & 0.43 & 0.268 & 0.187 & 0.0744 & 0.050 & $\begin{array}{l}\text { Inception } \\
\text { /Juvenile }\end{array}$ & $\begin{array}{l}\text { Single- } \\
\text { aliquot }\end{array}$ & USU-2011 & Ellerton et al., 202 \\
\hline 2 & 0.36 & 0.36 & 0.11 & 0.249 & 0.61 & 0.423 & 0.205 & 0.0551 & 0.027 & Juvenile & $\begin{array}{l}\text { Single- } \\
\text { aliquot }\end{array}$ & USU_2002 & Ellerton et al., 201 \\
\hline 3 & 0.43 & 0.43 & 0.06 & 0.101 & 0.57 & 0.272 & 0.147 & 0.0476 & 0.030 & Juvenile & $\begin{array}{l}\text { Single- } \\
\text { aliquot }\end{array}$ & USU-2010 & Ellerton et al., 202 \\
\hline 4 & 0.44 & 0.44 & 0.10 & 0.421 & 2.14 & 0.316 & 0.200 & 0.0383 & 0.025 & Juvenile & $\begin{array}{l}\text { Single- } \\
\text { aliquot }\end{array}$ & USU-2283 & Ellerton et al., 202 \\
\hline 5 & 1.94 & 1.94 & 0.28 & 0.155 & 1.00 & 0.276 & 0.121 & 0.0302 & 0.017 & Adolescence & $\begin{array}{l}\text { Single- } \\
\text { aliquot }\end{array}$ & USU-2267 & Ellerton et al., 202 \\
\hline 6 & 3.53 & 3.53 & 0.38 & 0.143 & 1.61 & 0.299 & 0.110 & 0.0210 & 0.013 & Mature & $\begin{array}{l}\text { Single- } \\
\text { aliquot }\end{array}$ & USU-2012 & Ellerton et al., 202 \\
\hline 7 & 3.60 & 3.60 & 0.30 & 0.270 & 1.75 & 0.228 & 0.091 & 0.0162 & 0.011 & Mature & $\begin{array}{l}\text { Single } \\
\text { grain }\end{array}$ & $\begin{array}{l}\text { Sample } \\
\text { Number } 2\end{array}$ & Walker et al., 2018 \\
\hline 8 & 4.20 & 4.20 & 0.40 & 1.02 & 2.45 & 0.240 & 0.136 & 0.0214 & 0.013 & Mature & $\begin{array}{l}\text { Single } \\
\text { grain }\end{array}$ & $\begin{array}{l}\text { Sample } \\
\text { Number } 3\end{array}$ & Walker et al., 2018 \\
\hline 9 & 4.89 & 4.89 & 0.45 & 0.469 & 1.96 & 0.195 & 0.127 & 0.0187 & 0.013 & Mature & $\begin{array}{l}\text { Single- } \\
\text { aliquot }\end{array}$ & USU-2284 & Ellerton et al., 202 \\
\hline \multirow{2}{*}{10} & 6.96 & \multirow{2}{*}{6.44} & \multirow{2}{*}{0.66} & \multirow{2}{*}{0.761} & \multirow{2}{*}{2.89} & \multirow{2}{*}{0.236} & \multirow{2}{*}{0.143} & \multirow{2}{*}{0.0154} & \multirow{2}{*}{0.009} & \multirow{2}{*}{ Mature } & $\begin{array}{l}\text { Single- } \\
\text { aliquot }\end{array}$ & USU-2269 & Ellerton et al., 202 \\
\hline & 5.91 & & & & & & & & & & $\begin{array}{l}\text { Single- } \\
\text { aliquot }\end{array}$ & USU-2268 & Ellerton et al., 202 \\
\hline \multirow{2}{*}{11} & 9.80 & \multirow{2}{*}{8.00} & \multirow{2}{*}{0.80} & \multirow{2}{*}{8.19} & \multirow{2}{*}{6.31} & \multirow{2}{*}{0.131} & \multirow{2}{*}{0.109} & \multirow{2}{*}{0.0125} & \multirow{2}{*}{0.008} & \multirow{2}{*}{ Mature } & $\begin{array}{l}\text { Single } \\
\text { grain }\end{array}$ & $\begin{array}{l}\text { Sample } \\
\text { Number } 5\end{array}$ & Walker et al., 2018 \\
\hline & 6.20 & & & & & & & & & & $\begin{array}{l}\text { Single } \\
\text { grain }\end{array}$ & $\begin{array}{l}\text { Sample } \\
\text { Number } 4\end{array}$ & Walker et al., 2018 \\
\hline 12 & 8.17 & 8.17 & 0.82 & 0.792 & 2.69 & 0.167 & 0.110 & 0.0131 & 0.008 & Mature & $\begin{array}{l}\text { Single- } \\
\text { aliquot }\end{array}$ & USU-2282 & Ellerton et al., 202 \\
\hline \multirow{2}{*}{13} & 9.74 & \multirow{2}{*}{9.02} & \multirow{2}{*}{0.80} & \multirow{2}{*}{4.30} & \multirow{2}{*}{4.55} & \multirow{2}{*}{0.137} & \multirow{2}{*}{0.122} & \multirow{2}{*}{0.0121} & \multirow{2}{*}{0.007} & \multirow{2}{*}{ Mature } & $\begin{array}{l}\text { Single- } \\
\text { aliquot }\end{array}$ & USU-2748 & Ellerton et al., 202 \\
\hline & 8.30 & & & & & & & & & & $\begin{array}{l}\text { Single } \\
\text { grain }\end{array}$ & $\begin{array}{l}\text { Sample } \\
\text { Number } 6\end{array}$ & Walker et al., 2018 \\
\hline 14 & 9.10 & 9.10 & 0.96 & 0.727 & 2.76 & 0.214 & 0.129 & 0.0150 & 0.009 & Mature & $\begin{array}{l}\text { Single- } \\
\text { aliquot }\end{array}$ & USU-2270 & Ellerton et al., 202 \\
\hline 15 & 9.82 & 9.82 & 0.98 & 1.81 & 3.26 & 0.160 & 0.116 & 0.0121 & 0.008 & Mature & $\begin{array}{l}\text { Single- } \\
\text { aliquot }\end{array}$ & USU-2285 & Ellerton et al., 202 \\
\hline
\end{tabular}

639

640

641

642

Extended Table 2: Defining landscapes evolutionary stages of development for the Cooloola Sand Mass,

Australia 24,49

\begin{tabular}{|c|c|c|c|c|}
\hline $\begin{array}{l}\text { Dune } \\
\text { development }\end{array}$ & Description & Dominate transport processes & $\begin{array}{l}\text { Secondary transport } \\
\text { processes }\end{array}$ & $\underline{\text { Soil development }}$ \\
\hline Inception & $\begin{array}{l}\text { Dune creation. Active landform constructed with little to no } \\
\text { vegetation. }\end{array}$ & $\begin{array}{l}\text { Wind advection, granular flows, and } \\
\text { deflation. }\end{array}$ & $\begin{array}{l}\text { Dry ravelling, granular } \\
\text { relaxation, and rain- } \\
\text { splash }\end{array}$ & No podzolization \\
\hline Juvenile & $\begin{array}{l}\text { Newly stabilized dune with vegetation. Some sections may contain } \\
\text { active (inception) features. Gradients are steep, with lee facing } \\
\text { slopes near } 0.65 \mathrm{~m}^{-1} \text { ( } 33^{\circ} \text { degrees). Sharp crest and trailing arms. } \\
\text { Episodic mass movement is the dominate transport process. }\end{array}$ & $\begin{array}{l}\text { Granular flows, sheet-washing, and } \\
\text { dry ravelling }\end{array}$ & $\begin{array}{l}\text { Dry ravelling, granular } \\
\text { relaxation, and rain- } \\
\text { splash }\end{array}$ & $\begin{array}{l}\text { Incipient Podzol } \\
\text { (weak B-horizon) }\end{array}$ \\
\hline Adolescence & $\begin{array}{l}\text { Stabilized dune with vegetation. Gradients remain steep with sharp } \\
\text { crest and trailing arms. Transitional phase of a dunes development } \\
\text { with little episodic mass movement. }\end{array}$ & $\begin{array}{l}\text { Granular flows, sheet-washing, dry } \\
\text { ravelling, soil creep, rain-splash and } \\
\text { granular relaxation }\end{array}$ & NA & $\begin{array}{l}\text { Podzol } \\
\text { (well defined B- } \\
\text { and E-horizons) }\end{array}$ \\
\hline Mature & $\begin{array}{l}\text { Stabilized dune with vegetation. Diffuse hillslopes with rounded } \\
\text { crests. Gradients are less than } 0.65 \mathrm{~m}^{-1} \text { ( } 33 \text { degrees) and no } \\
\text { episodic mass movement is present. Continuous soil creep } \\
\text { controls the development of the dunes evolution. }\end{array}$ & $\begin{array}{l}\text { Soil creep, rain-splash and granular } \\
\text { relaxation }\end{array}$ & NA & $\begin{array}{l}\text { Podzol } \\
\text { (well defined B- } \\
\text { and E-horizons) }\end{array}$ \\
\hline Old age & $\begin{array}{l}\text { Lack many of the dune original structures. Diffuse hillslope with no } \\
\text { episodic mass movement. Continuous soil creep controls the } \\
\text { development of the dunes evolution. }\end{array}$ & $\begin{array}{l}\text { Soil creep, rain-splash and granular } \\
\text { relaxation }\end{array}$ & NA & $\begin{array}{l}\text { Giant Podzol } \\
\text { (E-horizon }>5 \mathrm{~m} \text { ) }\end{array}$ \\
\hline
\end{tabular}




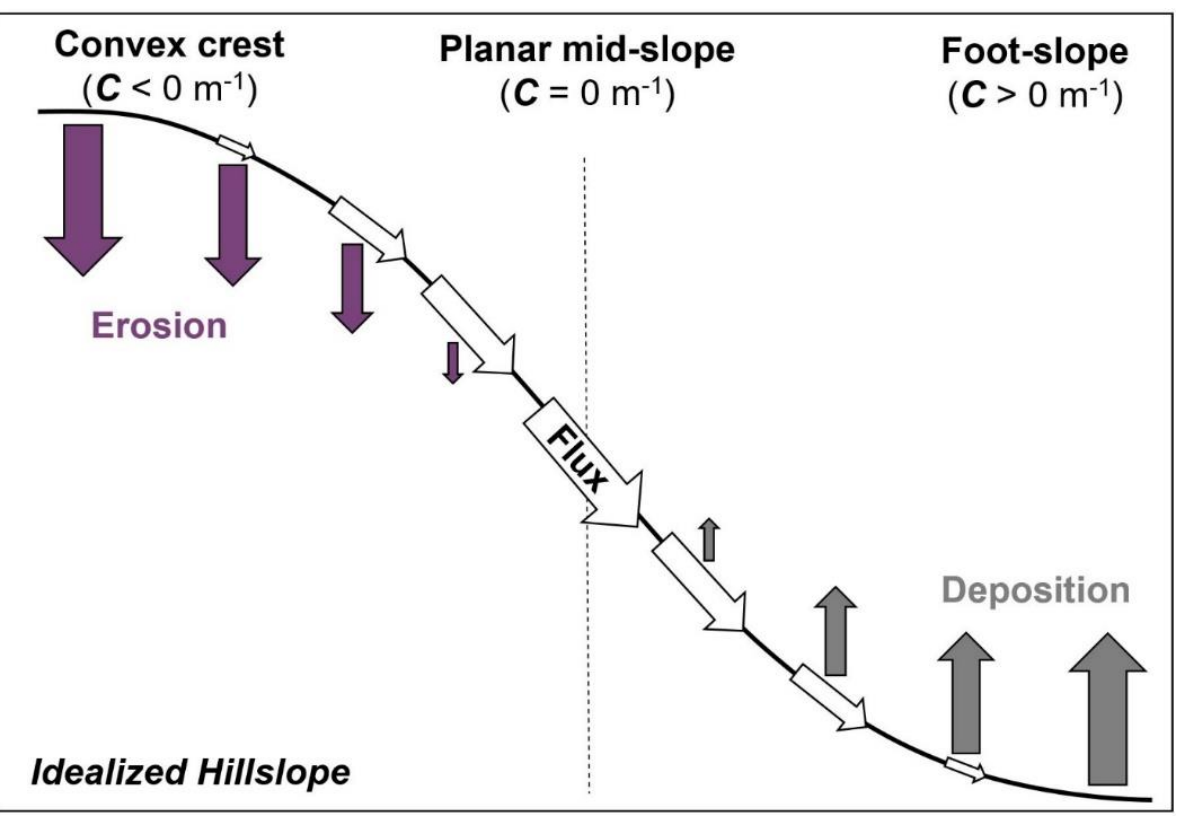

Extended Figure 1: Conceptual diagram of hillslope positions and the contribution of erosion, deposition and flux (size of arrow) at Cooloola Sand Mass (CSM), Australia. At the CSM, diffusive hillslope processes dominate and all sediment removed from crest and ridges can be accounted for in the hollows and valleys (a conservation of mass). Here we show that sediment flux is proportional to hillslope gradient (slope-dependent linear transport). At the crest, hillslope gradients and curvatures are low and erosion rates are the highest. Moving further downslope, away from the crest, hillslope gradients and curvatures increase causing more sediment flux and less erosion. A maximum sediment flux (equivalent to maximum erosion rate at the crest and a maximum deposition rate at the foot-slope) is reached at the mid-slope position when gradients are the highest and curvature is equal to $0 \mathrm{~m}^{-1}$. After the mid-slope position, only sediment flux and deposition occurs as hillslope gradients and curvatures decrease. At the foot-slope, hillslope gradients are low and curvature is at a minimum therefore deposition is at a maximum. As time progresses ridges lower and hollows fill, reducing hillslope gradients and the maximum and minimum curvature values. Combined we see a systematic decrease in erosion, deposition and flux rates with time.

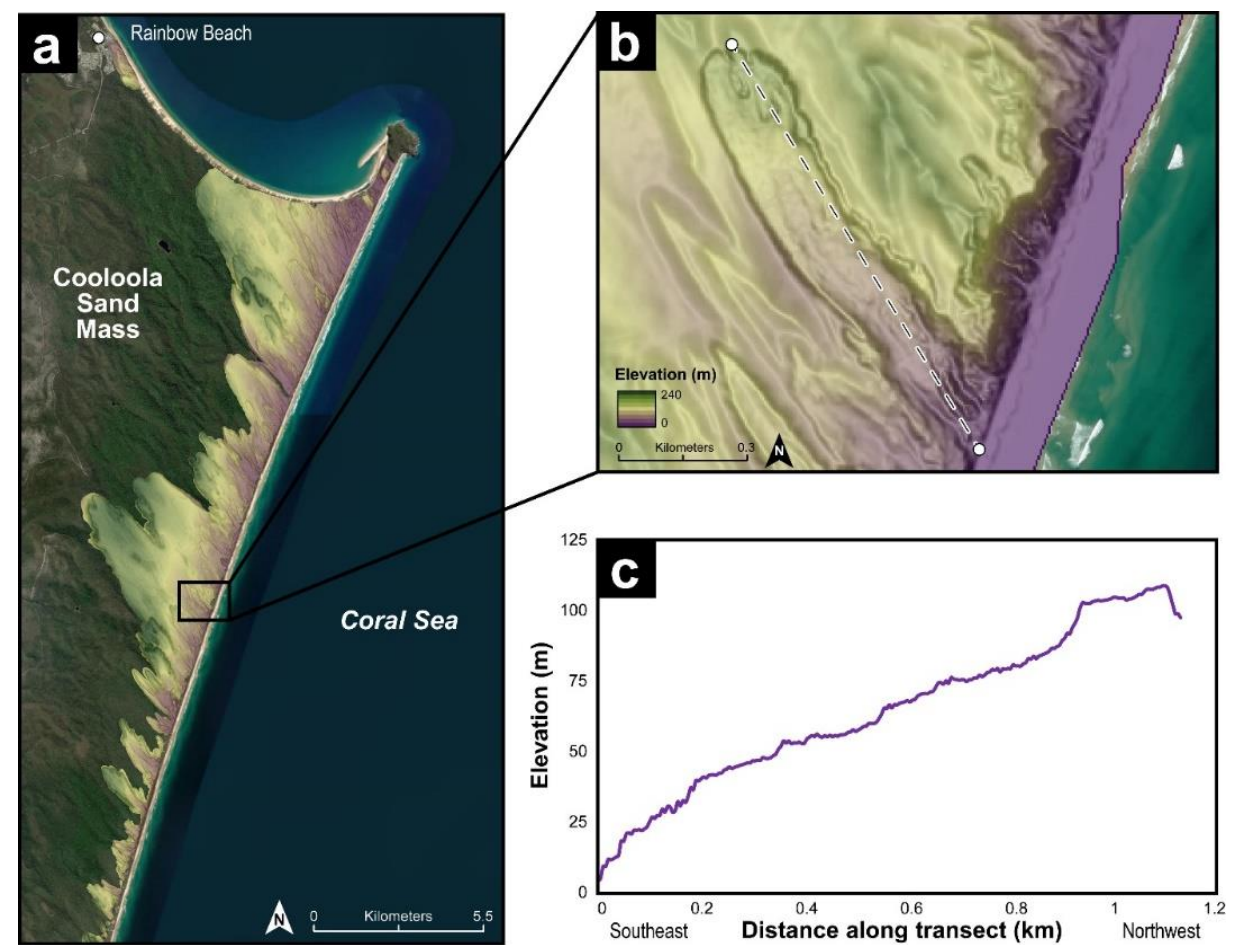

Extended Figure 2: Location of dune used in modelled simulations. a) Location of the $0.3 \mathrm{ka}^{49}$ dune and the $1.13 \mathrm{~km}$ transect used to run our 1-D landscape evolution model. b) Dune elevation profile from Southeast to Northwest. 

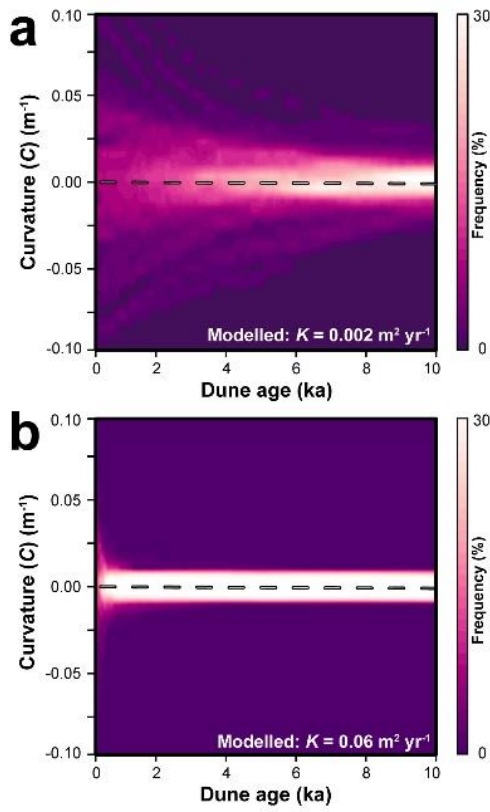
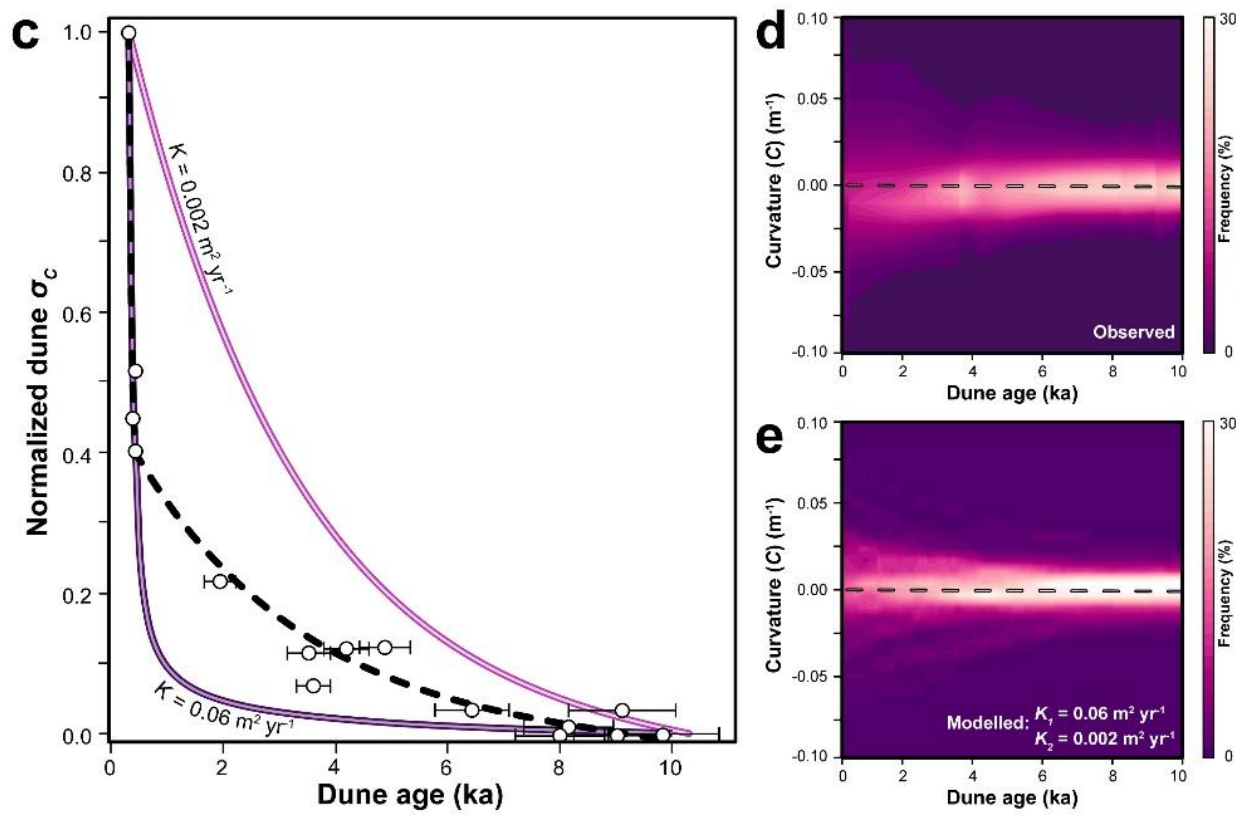

665

666

667

668

669

670

671

672

673

Extended Figure 3: Simulated verses observed landscape evolution results. Distributions of curvatures for simulated dune evolution for $10 \mathrm{ka}$ on a juvenile dune with a constant soil transport coefficient (K) values of a) $0.002 \mathrm{~m}^{2} \mathrm{yr}^{1}$ and $\left.\boldsymbol{b}\right) 0.06 \mathrm{~m}^{2} \mathrm{yr}^{1}$. Normalized modelled dune evolution from panels $\boldsymbol{a}$ (pink line) and $\boldsymbol{b}$ (purple line), compared to the observed CSM dune's $\boldsymbol{\sigma}_{c}$ (white dots). Not one $\boldsymbol{K}$ value alone can explain the evolution of the CSM dunes. Dunes are best described with a $\mathrm{K}$ value $0.06 \mathrm{~m}^{2} \mathrm{yr}^{1}$ before the hillslope threshold ( 0.03 $\mathrm{m}$-1) has been reached, after which a $\boldsymbol{K}$ value of $0.0012 \mathrm{~m}^{2} \mathrm{yr}^{1}$ can be prescribed, as depicted by the dashed line. Observed $\boldsymbol{C}$ distributions for the CSM dunes $\boldsymbol{d}$ ) parallel that of the two $\boldsymbol{K}$ value simulation e) utilized in panel c. Note, to compare our 1-D modelled simulation, we used profile curvature. Both hillslope curvature and profile curvature response similarly with time, see Extended Table 1.
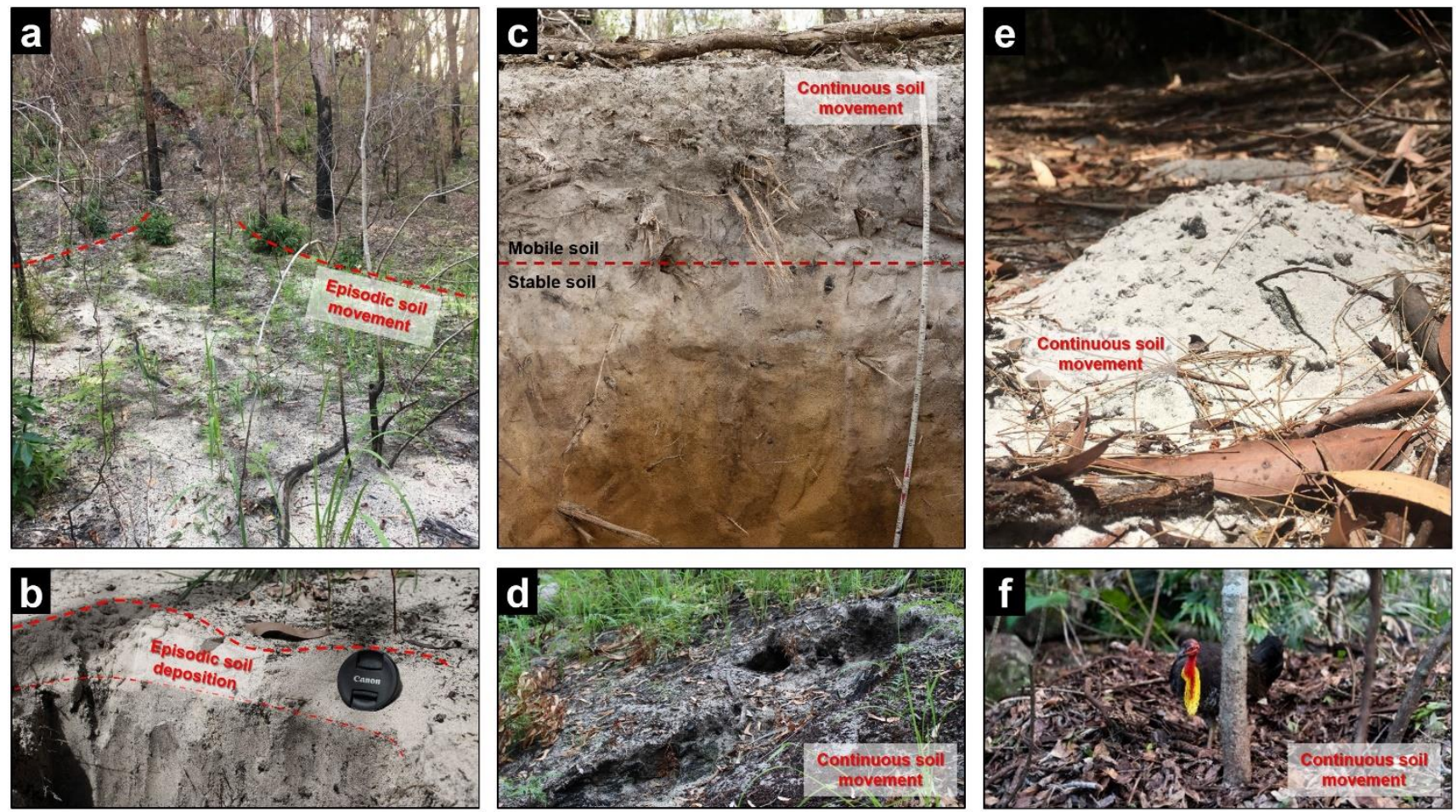

Extended Figure 4: Field images of typical soil movement. Commonly observed episodic (Panels a and b) and continuous (Panels $\boldsymbol{c}, \boldsymbol{d}, \boldsymbol{e}$ and $\boldsymbol{f}$ ) soil transport mechanisms at the Cooloola Sand Mass. a) Fire induced sand ravel and sheet-wash movement on the steep lee facing hillslope of a 0.44 ka dune shortly after fire event and its associated b) deposition. c) Common mid-slope soil profile on a Holocene age dune highlighting the abundance of biogenic disturbed soil near the surface in the A-horizon where it becomes increasingly stabile moving down profile as shown by the intact $E$ - and B-horizons. Typical perturbation include c) root growth and decay, d) tree throw, $\mathbf{e})$ burrowing invertebrates, and f) nest construction (photo credit: Patrick Adams and Kegham Hovsepian). 


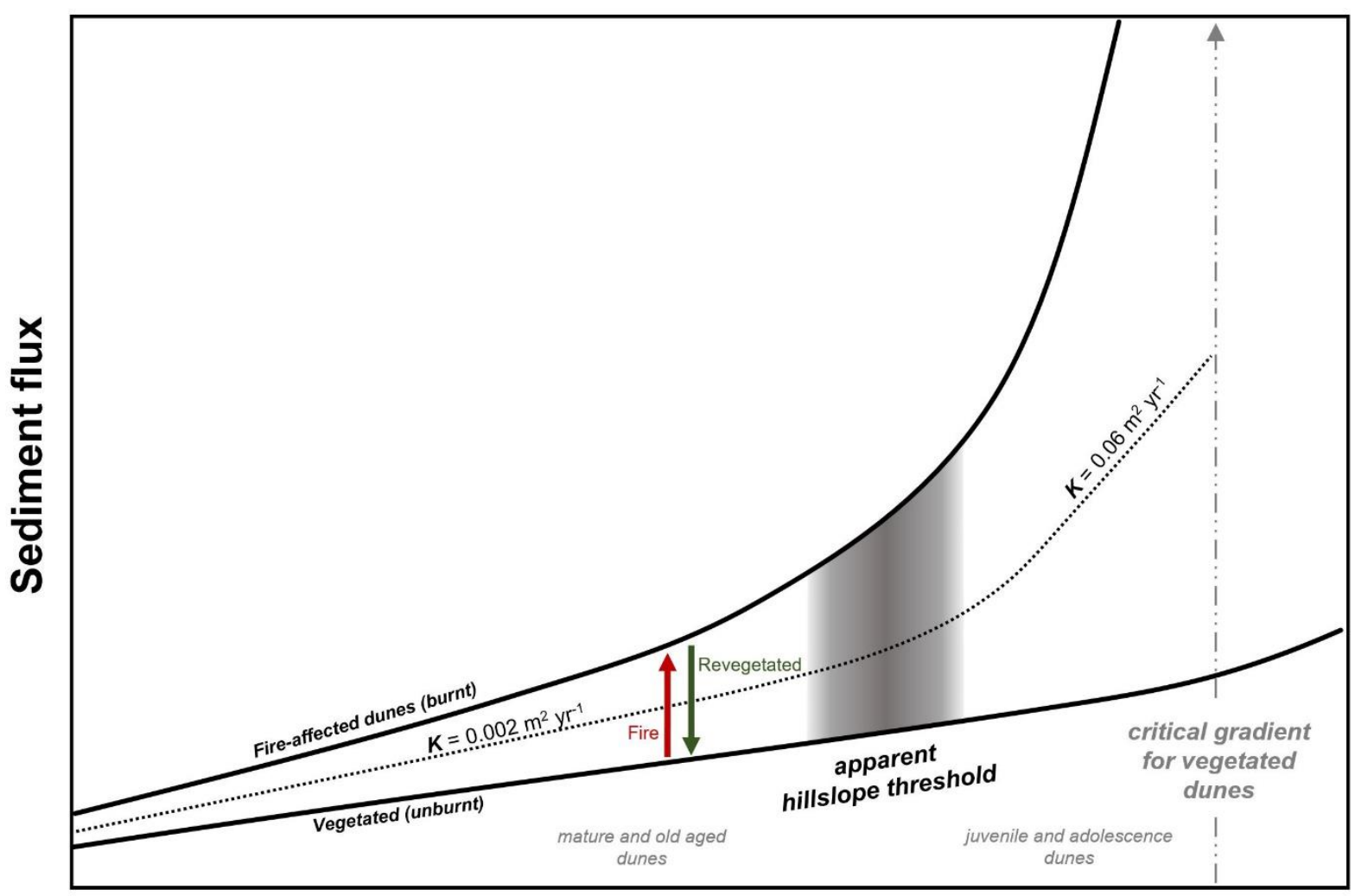

\section{Gradient}

Extended Figure 5: Conceptual diagram of sediment flux and gradient modified from Roering et al. ${ }^{35}$. When dunes are vegetated soil transport is muted and soil flux is linearly related to hillslope gradient. After fires, when sand is exposed and surfaces are hydrophobic, soil flux increases non-linearly with gradient, but the non-linearity of transport is only important for young dunes where slopes approach the critical hillslope gradient. The net effect of vegetated and burnt phases is a soil flux-gradient relationship that can be approximated by two straight line segments separated by an apparent threshold. Comparing our model simulations of $\boldsymbol{\sigma}_{c}$ time decay with empirical data suggest $K$ values of 0.002 and $0.06 \mathrm{~m}^{2} \mathrm{y}^{-1}$ approximate the behaviour, respectively, of older dunes with few steep slopes and low $\boldsymbol{\sigma}_{c}$; and younger dunes of steeper slopes and higher $\boldsymbol{\sigma}_{c}$. 


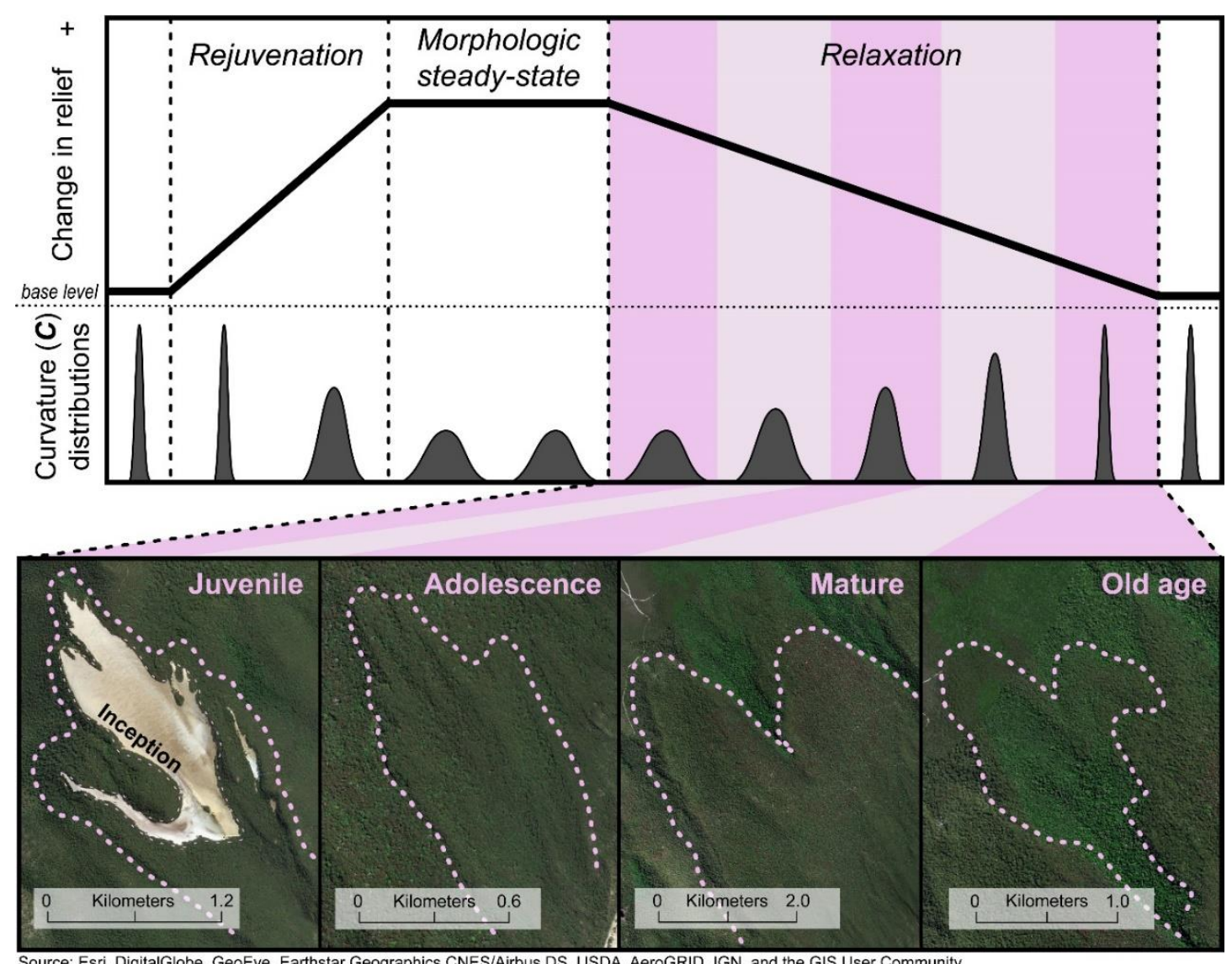

Extended Figure 6: Conceptual diagram (summarizes the main findings) modified from Montgomery ${ }^{3}$. The relationship between change in elevation from base level and dunes curvature $(\boldsymbol{C})$ distributions $\left(\boldsymbol{\sigma}_{C}\right)$ for a landscape with time. Positive change from base level represents a phase of landscape rejuvenation. This will result in a broadening in the $\boldsymbol{C}$ distribution (greater $\boldsymbol{\sigma}_{c}$ ) thus providing a higher potential for landscape change. No change in elevation with time (constant elevation) results in a morphologic steady-state. While negative change from base level represents a relaxation phase. This will result in a narrowing in the $\boldsymbol{C}$ distribution (lower $\boldsymbol{\sigma}_{C}$ ) thus providing a lower potential for landscape change. Given ample time in a relaxation phase, the landscape will evolve towards senescence $\left(\sigma_{c} \rightarrow 0 \mathrm{~m}^{-1}\right)$ where no local relief remains. The evolution of the dunes found at Cooloola Sand Mass (CSM) are constrained by hillslope thresholds which relate to physical properties of the original parent material (the angle of repose of the dry, unconsolidated sediment). Therefore, the $\sigma_{c}$ for dune inception is uniform and once emplaced will only decrease with time, unless reactivation occurs (rejuvenation). Aerial image of the delineated dunes and the stage of their evolutionary development highlight these changes. Further description of dune stages can be found in Extended Table 1 and 2. 
Figures
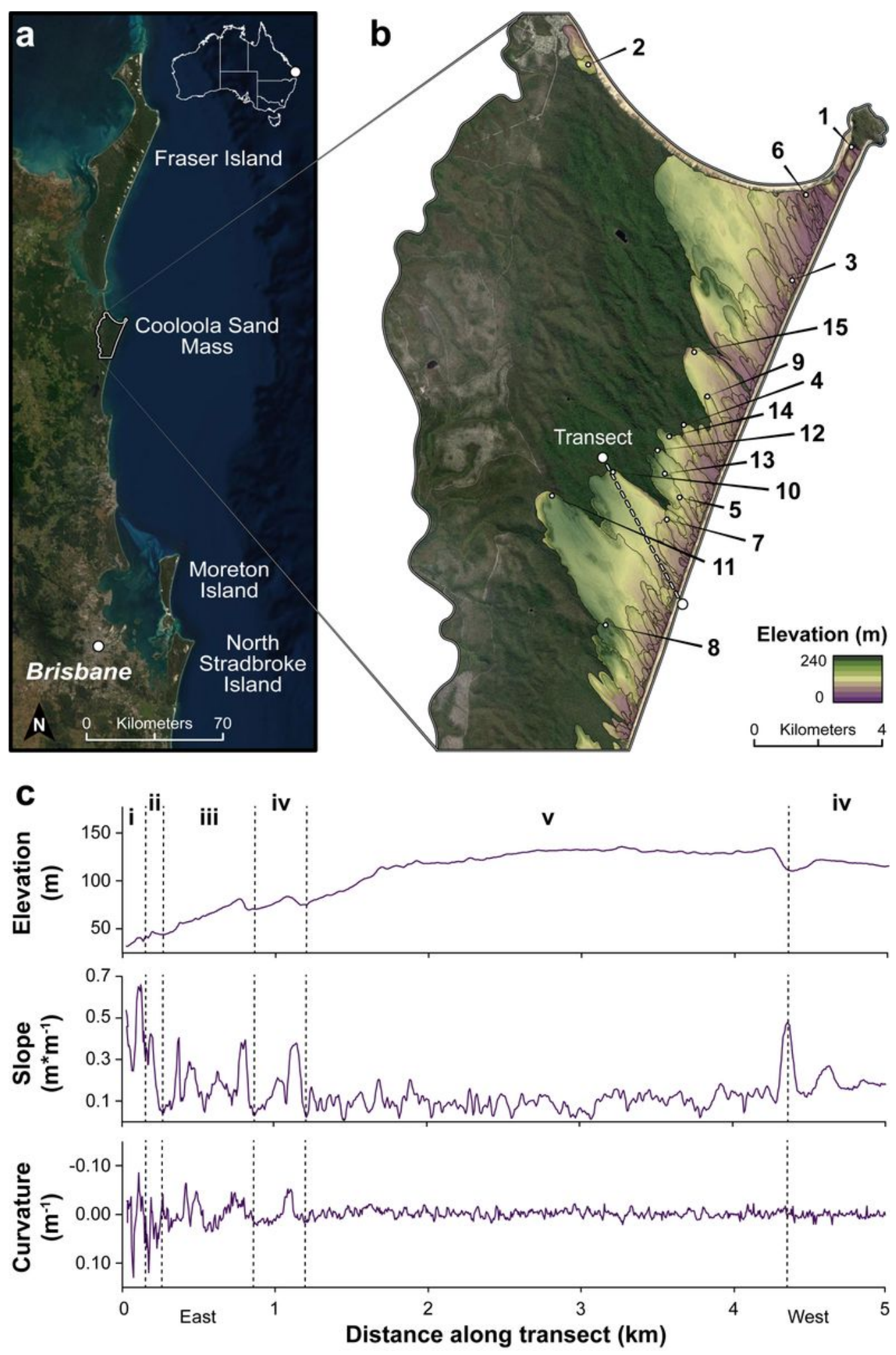

\section{Figure 1}

Regional and site location. a) Satellite imagery of the South East Queensland Dune fields in Australia, emphasizing the location of the Cooloola Sand Mass. b) Delineated Holocene dunes and their associated elevation at a $5 \mathrm{~m}$ resolution and location of the 15 dated dunes used in this study (dots) (obtained from 
Walker et al.23 and Ellerton et al.24, see Extended Table 1). c) A transect aligned parallel to the dominant wind direction, (southeast to northwest), seen in Panel b, highlights the transition from juvenile dunes (i) to more mature dunes (ii to vi). When dunes are emplaced, they have highly variable surface topography but as time continues, their slope relaxes towards a morphologic steady-state and this evolution can best be described by a dune's curvature (C), specifically a dune's standard deviation of curvature $(\sigma C)$.
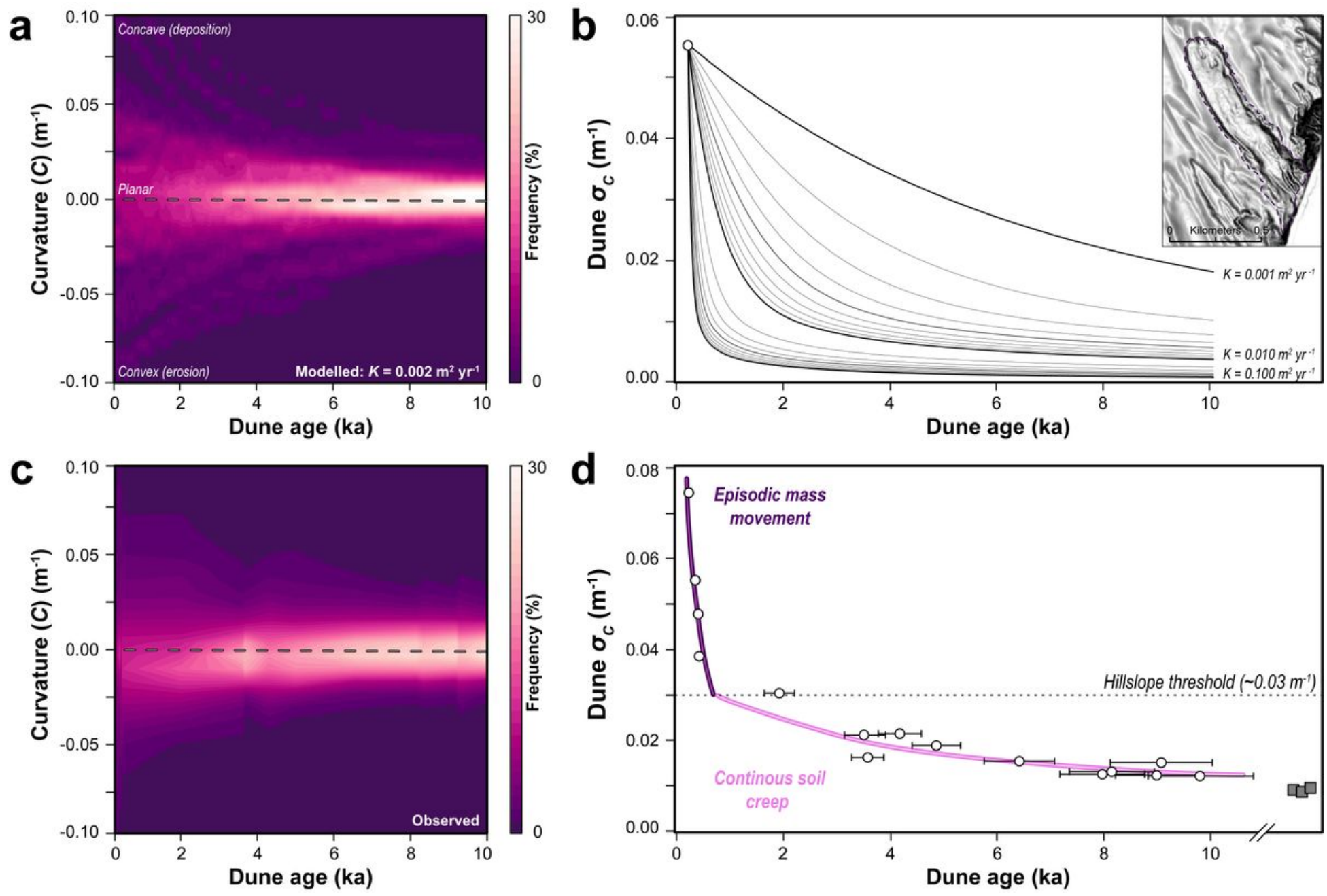

Figure 2

Simulated verses observed landscape evolution. a) Distributions of curvatures for simulated evolution of a juvenile dune (insert in panel b) with a constant soil transport coefficient (K) value of $0.002 \mathrm{~m} 2 \mathrm{yr}-1$, see Extended Fig. 2 and 3. Note the normal distribution of curvature (C) centred on planar topography (0 m-1) and the gradual narrowing of distributions with time (dark to light frequency). b) Simulated evolution of dune standard deviation of curvature $(\sigma \mathrm{C})$ for $10 \mathrm{ka}$, under varying $\mathrm{K}$ values. $\mathrm{c}$ ) Observed $\mathrm{C}$ distributions for the 15 dated CSM dunes which mirror simulated outcomes in Panel a. d) Plotted dune $\sigma \mathrm{C}$ with time (with error bars, $\pm 1 \sigma$ ), white dots and visual trend line. CSM evolution is best described by two $\mathrm{K}$ values. When dunes $\sigma \mathrm{C}$ are greater than the hillslope threshold ( 0.03 $\mathrm{m}-1$, dashed line), $\mathrm{K}$ is $0.06 \mathrm{~m} 2 \mathrm{yr}-1$ (purple line) which reflects the dominance of episodic mass movement (dry ravel and sheet-wash $(n=4)$ ). After dunes are lowered below the hillslope threshold, $\mathrm{K}$ is $0.002 \mathrm{~m} 2 \mathrm{yr}-1$ (pink line) where slow and continuous soil transport occurs (soil creep $(n=11)$ ), see Extended Fig. 3. This behaviour continues as a morphologic 
steady-state approximated by Pleistocene age dunes (grey squares, not included in this analysis) is approached.
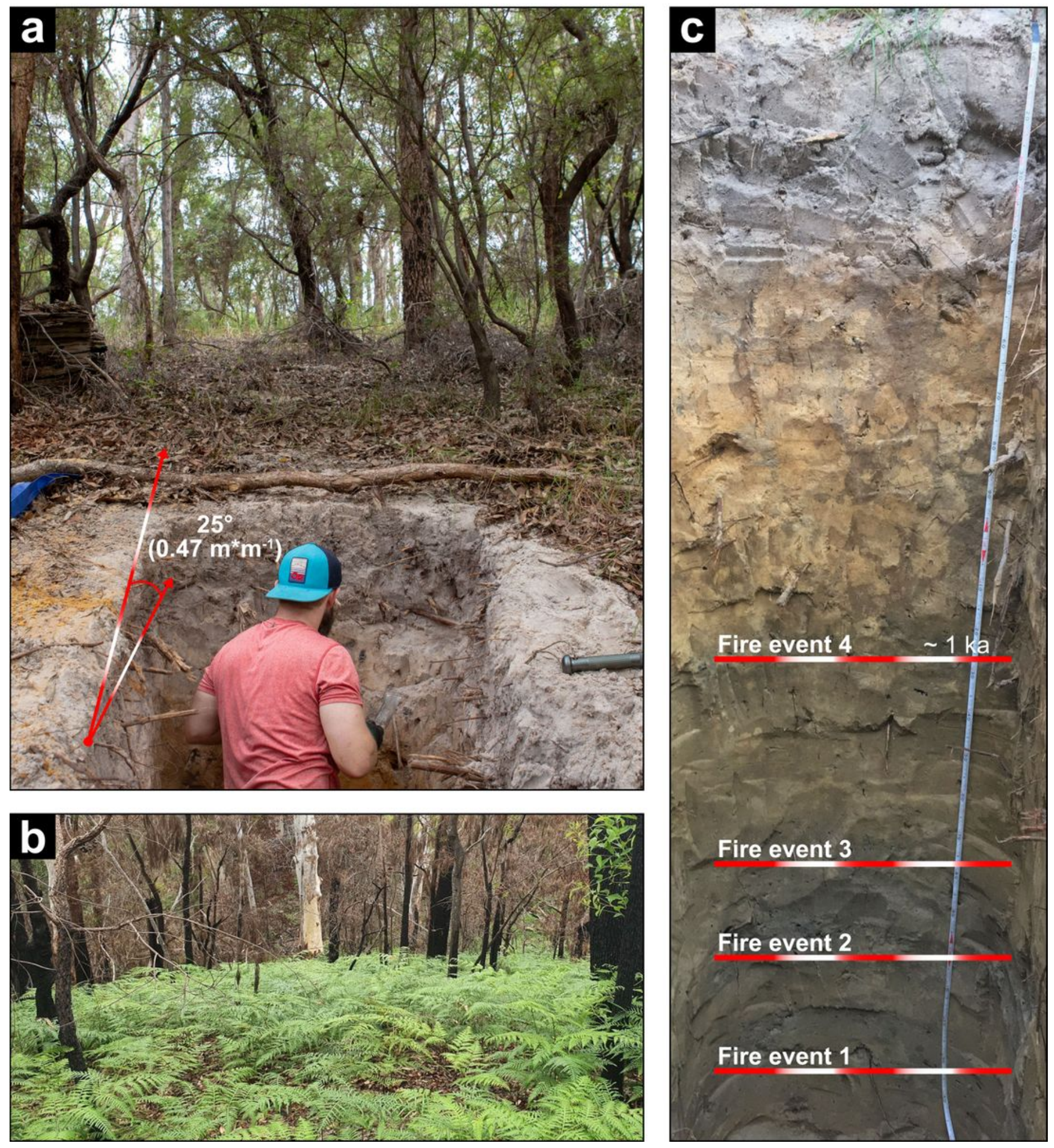

\section{Figure 3}

Surface images of dune slopes and soil profiles. a) Typical hillslope at the Cooloola Sand Mass looking up to dune crest. b) Same dune as Panel a looking down slope after being severely burnt in the "Freshwater Road Fire" on December 15th, 2019. Note, within three months the rapid reestablishment of 
vegetation covers and stabilizes the landscape. c) Depositional foot-slope of a 2 ka dune and stratified layers of charcoal associated with fire induced mass movement (dry ravelling and sheet-washing) oldest (fire event \#1) to youngest (fire event \#4). Distinct layers can be observed within the first $1 \mathrm{ka}$ (unpublished charcoal radiocarbon age) of dune deposition. As time progresses, charcoal layers become more diffuse and eventually become disseminated evenly throughout the profile, highlighting the transition between episodic to continuous sediment transport on dune evolution.

\section{Supplementary Files}

This is a list of supplementary files associated with this preprint. Click to download.

- SuppExtendedTable1.jpg

- SuppExtendedTable2.jpg

- SuppExtendedFigure1.jpg

- SuppExtendedFigure2.jpg

- SuppExtendedFigure3.jpg

- SuppExtendedFigure4.jpg

- SuppExtendedFigure5.jpg

- SuppExtendedFigure6.jpg 